\title{
Review Article \\ Effect of Insulin on Proximal Tubules Handling of Glucose: A Systematic Review
}

\author{
Ricardo Pereira-Moreira $(\mathbb{D})$ and Elza Muscelli \\ Department of Internal Medicine, School of Medical Sciences, University of Campinas, Zip Code: 13083-887, Brazil \\ Correspondence should be addressed to Ricardo Pereira-Moreira; 80ricardomoreira@gmail.com \\ and Elza Muscelli; muscellie@gmail.com
}

Received 29 September 2019; Revised 18 December 2019; Accepted 27 December 2019; Published 10 January 2020

Academic Editor: Carla Iacobini

Copyright (c) 2020 Ricardo Pereira-Moreira and Elza Muscelli. This is an open access article distributed under the Creative Commons Attribution License, which permits unrestricted use, distribution, and reproduction in any medium, provided the original work is properly cited.

Renal proximal tubules reabsorb glucose from the glomerular filtrate and release it back into the circulation. Modulation of glomerular filtration and renal glucose disposal are some of the insulin actions, but little is known about a possible insulin effect on tubular glucose reabsorption. This review is aimed at synthesizing the current knowledge about insulin action on glucose handling by proximal tubules. Method. A systematic article selection from Medline (PubMed) and Embase between 2008 and 2019. 180 selected articles were clustered into topics (renal insulin handling, proximal tubule glucose transport, renal gluconeogenesis, and renal insulin resistance). Summary of Results. Insulin upregulates its renal uptake and degradation, and there is probably a renal site-specific insulin action and resistance; studies in diabetic animal models suggest that insulin increases renal SGLT2 protein content; in vivo human studies on glucose transport are few, and results of glucose transporter protein and mRNA contents are conflicting in human kidney biopsies; maximum renal glucose reabsorptive capacity is higher in diabetic patients than in healthy subjects; glucose stimulates SGLT1, SGLT2, and GLUT2 in renal cell cultures while insulin raises SGLT2 protein availability and activity and seems to directly inhibit the SGLT1 activity despite it activating this transporter indirectly. Besides, insulin regulates SGLT2 inhibitor bioavailability, inhibits renal gluconeogenesis, and interferes with $\mathrm{Na}^{+} \mathrm{K}^{+}$ATPase activity impacting on glucose transport. Conclusion. Available data points to an important insulin participation in renal glucose handling, including tubular glucose transport, but human studies with reproducible and comparable method are still needed.

\section{Introduction}

Diabetes global prevalence almost doubled in the last three decades. This disorder is a major cause of kidney failure, up to $44 \%$ of world end-stage renal disease, beyond ten times dialysis need and renal transplantation [1]. Kidneys are the leading organs involved in insulin clearance from the systemic circulation [2]. They contribute to endogenous glucose production through gluconeogenesis, primarily in proximal tubule (PT) cells [3] under glucose and insulin regulation [4]. Furthermore, PTs reabsorb glucose following its glomerular filtration, through the sodium-glucose linked transporters (SGLTs), mainly the SGLT2 located on the luminal surface of PT cells [5]. Consequently, renal glucose handling also depends on glucose glomerular filtration $[6,7]$ and on the degree of kidney damage [8].

The insulin effect has been extensively studied in renal sodium handling [9]. There is also evidence of direct [10] and indirect [11] insulin effect on glomerular filtration and modulation of renal glucose expenditure [12-14]. However, its action on renal glucose transport is still little understood.

Renal glucose uptake in diabetic patients is higher than that in healthy individuals, even when renal function is maintained [15-19]. Adaptive or pathophysiological changes in glucose transporters related to acute $[20,21]$ or sustained hyperglycaemia [22-26] may partially explain such difference. Nonetheless, insulin lack or resistance should be taken into consideration too. 
High glucose absorption and flux, as in diabetes, may induce tubular damage via an SGLT2 dependent pathway $[27,28]$. The enhanced SGLT2 activity causes mitochondrial dysfunction through a more extensive glucose flux inside PT cells [29], resulting in high oxidative stress and cellular apoptosis [30-32]. Since insulin signalling directly preserves mitochondrial metabolism and function, insulin resistance can trigger mitochondrial dysfunction and damage [33] contributing to renal injury. Reciprocally, impaired mitochondrial function reduces insulin sensitivity [33]. These findings may explain the protective effect of SGLT2 inhibition on kidneys and suggested an intrinsic relationship between renal glucose transport and insulin signalling.

Insulin has been used as a diabetes therapy since 1921 [34]. It is the principal resource to treat type 1 diabetes (T1D) as well as type 2 diabetes (T2D) patients under oral treatment failure. New therapy options include the SGLT2 inhibitors (SGLTi) that block renal glucose reabsorption and can be used as monotherapy or as add-on oral antihyperglycaemic drugs or insulin, at least in T2D patients [35]. In this way, knowing the interactions between insulin and glucose transport by PTs is important to understand not only renal diabetes impairment but also interactions among therapy drugs, mainly of insulin with SGLT2i.

This review is aimed at describing and summarizing the current understanding of the insulin effect on PTs and at discussing the main points involved in this process.

\section{Methods}

Original studies, written in English, assessing primary or secondary insulin action on glucose handling by PTs in humans, animal models, tissues, or cell cultures were eligible for inclusion. Data source, between 2008 and June 2019, from Medline (PubMed) and EMBASE, was used. Articles important to the review understanding published before 2008 and described in the references of at least one selected article were included as well.

Search terms included the following: insulin, diabetes, T1D, T2D, renal, kidney, proximal tubule or tubules, GLUT, GLUT1, GLUT2, SGLT, SGLT1, SGLT2, and $\mathrm{Na}^{+} \mathrm{K}^{+}$ATPase derivative terms (for example, NKA, NaKAtpase, or NKpump). We performed a triple-term search in databases with insulin, diabetes, T1D, and T2D as the first term; renal, kidney, and proximal tubule or tubules as the second; and the transport proteins as the third one. After that, an inclusive, double-term search without the second designative term was performed only in PubMed.

Two reviewers (R.P.M. and E.M.) independently evaluated the titles and abstracts and then the full text for inclusion eligibility.

Intervention studies with SGLT2i that did not evaluate insulin effect on PTs as well as those regarding glomerular function or diabetic nephropathy not related to glucose transport were excluded. Studies about renal gluconeogenesis and renal insulin resistance were included because of the possible influence of those processes on PT glucose handling.

We developed a data extraction table considering the methods and outcomes of the selected studies. One investiga-

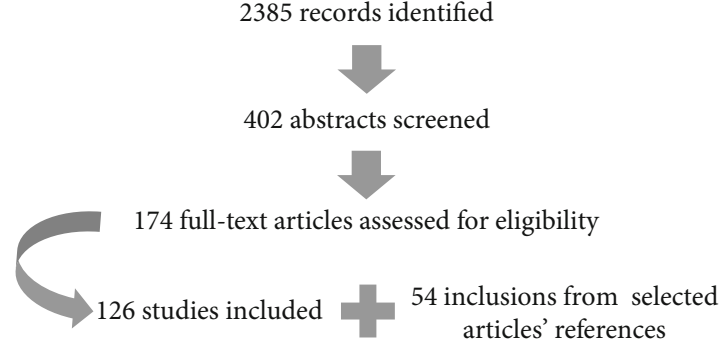

FIgURE 1: Literature flow diagram.

tor extracted the data (R.P.M.) and the other reviewed it (E.M.). The extracted data included general information (title, authors, and year of publication), type of study, objectives, methodological characteristics (humans, animal models, cell cultures, renal site of evaluation, insulin intervention, isolated insulin effect, type and duration of diabetes, and insulin therapy length), and main outcomes related to the review aims.

\section{Results}

The articles were selected as described in Figure 1.

A total of 2385 articles were selected. After title evaluation, 1983 articles were excluded (review, not related to kidneys, to insulin action, or to glucose handling) resulting in 402 articles for abstract selection. After abstracts analysis, 228 articles were excluded with the same criteria and 174 articles were selected for a full reading. Full reading resulted in 126 selected articles from the initial search, and more 54 articles were obtained from their references. Then, a total of 180 articles were included in this review. Other 32 papers including some reviews were used to introduce and explain our aim and the result topics. The selected articles were clustered into topics and used to construct the summary of evidence described below.

3.1. Renal Insulin Handling. Insulin handling by the kidneys and the hormone concentration differences along the renal capillaries and tubules will be described before its action on PTs to facilitate the understanding of insulin effect at PT level and emphasize its importance.

While the liver removes around 50\% of portal insulin during its first pass [36, 37], kidneys are the major organs responsible for the insulin clearance from the systemic circulation removing about $35 \%$ of total secreted insulin [2]. Most of this clearance occurs in the glomerulus impacting the hormone bioavailability in the tubular lumen and peritubular capillaries at PT level and other downstream nephron segments [2]. The majority of insulin is freely filtered in glomerular capillaries being virtually totally recovered by PT cells, predominantly across the brush border membrane (BBM), where insulin translocates through endocytic vesicles to vacuoles and then is degraded [2, 38]. Endocytosis occurs after insulin binding to the megalin-cubilin complex and, to a lesser extent, to the specific insulin receptors (IRecs) present on PT BBM. Megalin is a protein of the transmembrane complex that recovers the majority of serum proteins, including 
insulin. It is expressed in the PT proximal segment S1 and slightly in the intermediary S2 and distal S3 PT segments $[39,40]$. Insulin increases its own uptake and degradation by inducing a rise in megalin content [41]. Less than $1 \%$ of filtered insulin undergoes transcytosis to the basolateral membrane [42], and only $1 \%$ is excreted in the urine [43$45]$. The remaining nonfiltered insulin reaches the postglomerular peritubular circulation where insulin clearance takes place through specific IRecs binding mainly at PT level.

In PTs, insulin reaches its highest concentration and acts on gluconeogenesis suppression [12, 46,47] and, possibly, on glucose transport $[21,48,49]$. Furthermore, insulin is disposed in other tubular sites where IRecs are found in high density, like the medullary thick ascending limb of Henle's loop and the distal convoluted tubules where it stimulates sodium reabsorption $[50,51]$.

Insulin is degraded mainly by the enzyme protein disulfide isomerase, cathepsin $\mathrm{D}$, and especially the insulindegrading enzyme (IDE). IDE is upregulated by insulin in the central nervous system, but little is known about its renal regulation $[52,53]$. SNX5, a sorting nexin protein family, regulates intracellular trafficking and the expression of IRecs in PTs and upregulates IDE expression and function. The colocalization of IDE and SNX5 next to the BBM reduces insulin levels while deficiency of one or both regulators leads to increased circulating insulin levels decreasing IRec expression and inducing insulin resistance $[54,55]$.

3.2. Proximal Tubule Glucose Transport. In this section, results of experimental and clinical studies are described aiming at exploring the relationship between insulin signalling and its effect on PTs, on glucose excretion, and on renal glucose transporters, particularly in diabetes. The first topic is a brief description of renal glucose transporters, their localization, and function.

3.2.1. Renal Glucose Transport Proteins. Two protein families, GLUTs and SGLTs, are in charge of the glucose transport in PT S1, S2, and S3 segments [5, 56]. GLUTs, highly expressed in kidneys, are facilitative glucose transporters present ubiquitously on cellular surfaces, composing a saturable, stereoselective, and bidirectional transport system. While GLUT1 has a high affinity for glucose, GLUT2 is a low-affinity and high-capacity transporter also mediating galactose, mannose, and fructose transport [56]. SGLTs utilize the electrochemical sodium gradient to move glucose against its concentration gradient [5]. The two types of renal SGLTs, SGLT1 and SGLT2, differ in sodium to glucose stoichiometry, sugar selectivity, sites of expression, and regulation [5,57], even if one electrophysiological study has demonstrated similar affinities [58]. SGLT2 has higher transport capacity and is more able to adjust its glucose transport proportionally to glucose concentrations than SGLT1 [5].

In rats, GLUT1 is located in the S3 segment. It is also found in the thick limb of Henle's loop and collecting ducts $[59,60]$, metabolically active sites that consume large amounts of glucose as substrate [61]. GLUT2 expression has been demonstrated in the S1 segment $[60,62]$. SGLT1 is found along all PT segments $[59,63]$, and its density in the BBM and intracellular organelles increases from $\mathrm{S} 1$ to $\mathrm{S} 3$ being higher in the outer medulla than in the cortex $[63,64]$. SGLT2 is situated in the renal cortex [65], especially in the S1 and S2 segments [66,67], and its expression is higher in the former [66]. In humans, expression of SGLT2 protein occurs in S1 and S2 whereas SGLT1 is expressed in the S3 segment. The two proteins are present only on the BBM side [57]. To our knowledge, studies regarding GLUT2 tubular localization were not performed in human but its mRNA has been demonstrated in PT cells [68-70].

Studies in knockout mice for SGLT2 or SGLT1 or SGLT2 plus SGLT1 have demonstrated that SGLT2 reabsorbs $80 \%$ to $90 \%$ glucose of the glomerular filtrate while SGLT1 reabsorbs the remaining $10-20 \%$ [71]. However, under acute [72] or chronic [73] SGLT2 inhibition or in SGLT2 knockout mice $[73,74]$, a compensatory increase in SGLT1-mediated glucose transport explains $40-50 \%$ of its fractional reabsorption. This is observed early, even in the first hour of SGLT2 inhibition in murine models [72]. SGLT1 vicariance justifies the maintenance of until $50 \%$ of the normal fractional glucose reabsorption during selective SGLT2 inhibition in humans [75-77]. Besides, in rats, a higher SGLT1contribution was reported under euglycaemic or hypoglycaemic conditions than in hyperglycaemic conditions [78].

\subsubsection{Tubular Glucose Transporters in Animal Models of} Diabetes. In this topic, studies in diabetes models involving quantitative modification of a specific glucose transporter mRNA or protein were clustered (Table 1). This kind of study does not quantify the real dynamic function of the glucose transporters and their activity variation. However, all together, they can suggest transporter impairment in diabetes.

Most of the studies for GLUT1 evaluation in these models were carried out in streptozotocin (STZ) rats. They predominantly reported higher GLUT1 protein [79-82] and corresponding mRNA [81-85] contents in the whole kidney and increased GLUT1 protein $[86,87]$ and mRNA $[86,88,89]$ in the cortex. Nonetheless, these studies are yet controversial [22, 67, 90-93]. In STZ rats, S3 GLUT1 mRNA availability raised and returned to its normal values after one month of diabetes induction, while cortical (mainly S1 and S2 segments) GLUT1 remained at low levels until six months. Subsequent insulin treatment increased the cortical but did not change the S3 GLUT1 content [24]. On the contrary, in insulin-resistant animals, GLUT1 in the S3 segment decreased in the first 3 months of diabetes and increased in the next 3 months, when cortical GLUT2 activity enhanced [25]. So, GLUT1 seems to have a differentiated regulation depending on which tubular segment is evaluated, the insulin deficiency or resistance, and the diabetes duration.

Regarding GLUT2, the results of diabetes murine models are debatable $[22,24-26,79,83-85,87,90-100]$. In addition, many studies have been carried out in STZ rats $[24,26,79$, $83,85,87,90-93,96,98]$, and STZ induces diabetes through beta-cell apoptosis after being transported by GLUT2 [101]. Theoretically, the same can occur in the proximal portions of PTs where GLUT2 is coupled to SGLT2. This toxicity could change the proportions of active cells impairing the evaluation of these transporters $[101,102]$. In a STZ model, 
TABLE 1: Glucose transporter protein and mRNA availability in T1D and T2D murine models.

\begin{tabular}{|c|c|c|c|}
\hline & Results & Protein & mRNA \\
\hline \multicolumn{4}{|c|}{ GLUT1* } \\
\hline \multirow{3}{*}{ T1D } & Increased & {$[79-82]\left(\mathrm{STZ}^{\mathrm{WK}}\right) ;[86,87]\left(\mathrm{STZ}^{\mathrm{C}}\right)$} & {$[81-85]\left(\mathrm{STZ}^{\mathrm{WK}}\right) ;[86,88,89]\left(\mathrm{STZ}^{\mathrm{C}}\right)$} \\
\hline & Similar & [93] $\left(\mathrm{STZ}^{\mathrm{WK}}\right) ;[67,91]\left(\mathrm{STZ}^{\mathrm{C}}\right)$ & [93] $\left(\mathrm{STZ}^{\mathrm{WK}}\right)$ \\
\hline & Reduced & & {$[92]\left(\mathrm{STZ}^{\mathrm{WK}}\right)$} \\
\hline \multirow{3}{*}{$\mathrm{T} 2 \mathrm{D}$} & Increased & & {$[85]\left(\mathrm{db} / \mathrm{db}^{\mathrm{WK}}\right)$} \\
\hline & Similar & [90] $\left(\mathrm{GK}^{\mathrm{C}}\right) ;[90]\left(\mathrm{JK}^{\mathrm{C}}\right) ;[90]\left(\mathrm{HFD}^{\mathrm{C}}\right)$ & [22] $\left(\right.$ OLETF $\left.^{\mathrm{C}}\right)$ \\
\hline & Reduced & & {$[92]\left(\mathrm{GK}^{\mathrm{WK}}\right)$} \\
\hline \multicolumn{4}{|l|}{ GLUT2 } \\
\hline \multirow{3}{*}{ T1D } & Increased & {$[26,79,87,90,96]$ (STZ); [99] (Alloxan) } & [24, 83] (STZ); [84] (Akita); [97] (Alloxan) \\
\hline & Similar & [91] (STZ) & {$[85,91,92,93,98]$ (STZ); [96] (Akita) } \\
\hline & Reduced & [95] (Alloxan) & [95] (Alloxan) \\
\hline \multirow{2}{*}{$\mathrm{T} 2 \mathrm{D}$} & Increased & [25] (MG); [94] (Zucker) & [22] (OLETF); [100] (db/db $\left.{ }^{\S}\right)$ \\
\hline & Similar & [90] (GK); [90] (JK); [90] (HFD) & [85] (db/db); [92] (GK); [98] (HFD) \\
\hline \multicolumn{4}{|l|}{ SGLT1 } \\
\hline \multirow{3}{*}{ T1D } & Increased & [80] (STZ) & [83] (STZ); [84] (Akita) \\
\hline & Similar & & {$[93,98](\mathrm{STZ})$} \\
\hline & Reduced & [84] (Akita); [103] (STZ) & {$[85,92](\mathrm{STZ})$} \\
\hline \multirow[t]{2}{*}{$\mathrm{T} 2 \mathrm{D}$} & Increased & [90] (GK); [90] (JF); [103] (db/db); [105] $\left(\mathrm{HFD}^{\#}\right)$ & $\begin{aligned} {[104](\mathrm{OB} / \mathrm{OB}) ; } & {[100]\left(\mathrm{db} / \mathrm{db}^{\S}\right) ;[22](\mathrm{OLETF}) ;[106] } \\
& (\text { Zucker}) ;[92](\mathrm{GK})\end{aligned}$ \\
\hline & Similar & {$[100]\left(\mathrm{db} / \mathrm{db}^{\S}\right)$} & {$[98](\mathrm{HFD})$} \\
\hline \multicolumn{4}{|l|}{ SGLT2 } \\
\hline \multirow{3}{*}{ T1D } & Increased & $\begin{array}{c}{[32,67,107,108,109],[110]^{\mathrm{a}}(\mathrm{STZ}) ;[84,85] \text { (Akita); }} \\
{[99] \text { (Alloxan) }}\end{array}$ & {$[32,83,107,108,109]$ (STZ); [112] (Alloxan) } \\
\hline & Similar & [93] (STZ) & [93] (STZ) \\
\hline & Reduced & {$[85]^{\mathrm{b}},[113]^{\mathrm{a}, \mathrm{c}}(\mathrm{STZ})$} & {$[85]^{\mathrm{b}},[98](\mathrm{STZ})$} \\
\hline \multirow{3}{*}{$\mathrm{T} 2 \mathrm{D}$} & Increased & [90] (JF); [111] (db/db); [94] (Zucker) & $\begin{array}{c}{[85](\mathrm{db} / \mathrm{db}) ;[100]\left(\mathrm{db} / \mathrm{db}^{\S}\right) ;[22](\text { OLETF }) ;[106] \text { (Zucker); }} \\
{[104](\mathrm{OB} / \mathrm{OB})}\end{array}$ \\
\hline & Similar & {$[100]\left(\mathrm{db} / \mathrm{db}^{\S}\right) ;[105]\left(\mathrm{HFD}^{\#}\right)$} & \\
\hline & Reduced & & [98] (HFD) \\
\hline
\end{tabular}

Results were compared to the corresponding controls; numbers are references; the study model is inside the parentheses. $*$ Results for GLUT1 were specified for whole kidney (WK) or cortex (C) due to the different availability of GLUT1 in distinct nephron sites, while GLUT2, SGLT1, and SGLT2 are available only at proximal tubules level. a Short-duration diabetes. ${ }^{\mathrm{b}}$ Initially reduced followed by a partial recovery but maintaining lower levels. ${ }^{\mathrm{c}}$ Protein activity was also reduced. STZ: streptozotocin model; db/db: leptin receptor mutation model; GK: Goto-Kakizaki diabetic rats; HFD: high-fat diet; OLETF: Otsuka LongEvans Tokushima Fatty rats; MG: monosodium glutamate treatment. ${ }^{\S}$ Mix model with insulinopenic and insulin-resistant rats. ${ }^{\#}$ Insulin resistance without changes in glycaemic levels compared to controls.

the increased cortical GLUT2 mRNA availability was normalized after seven days of insulin replacement [24], but glycaemic changes could have modified the results, making their interpretation problematic.

Reports of SGLT1 protein $[80,84,103]$ and mRNA [83$85,92,93,98]$ contents in PTs of T1D murine models are also contradictory while in T2D models only mRNA expression seems to be upregulated [22, 90, 92, 98, 100, 103-106]. SGLT2 has been studied in many models of diabetes, and the results suggest increased protein $[32,67,84,85,90,94$, 99, 107-111] and mRNA [22, 32, 83, 85, 100, 104, 106-109, 112] contents and activity [108] despite some controversial results $[85,93,98,100,105,113]$.

In summary, T1D models showed increased GLUT1 in both the whole kidney and cortex. These changes can be transitory and site-specific. GLUT2 results are still controversial. SGLT1 results were concordant only regarding the upregula- tion of mRNA expression in T2D models. Studies frequently reported SGLT2 contents as increased in both models, a plausible reason for the higher renal glucose uptake of diabetic patients. However, whether transporter changes are due to high glycaemic levels or reduced insulin signalling or both is still an open question.

3.2.3. Tubular Glucose Transporters and Renal Glucose Handling in Diabetes: Human Studies. Renal glucose reabsorption is proportional to glycaemic increments until blood glucose levels exceed the renal threshold for glucose (RTG) when glucose starts to appear in the urine $[114,115]$. As glucose concentration rises above the RTG limit (around $10 \mathrm{mmol} / \mathrm{L}[5,15,16])$, the increment in the rate of tubular glucose reabsorption slows down in an initial nonlinear curve termed splay $[116,117]$. It is followed by a constant glucose reabsorption rate that has been studied since 1940 and 
defines the maximum renal glucose reabsorptive capacity (Tmax). After Tmax is reached, increments in blood glucose result in equal linear increments in glycosuria $[48,116,117]$.

Tmax for glucose is 15 to $20 \%$ higher in diabetic patients (356 to $463 \mathrm{mg} / \mathrm{min}$ ) compared to healthy subjects (303 to $404 \mathrm{mg} / \mathrm{min}$ ) $[15,16,48,118]$ despite RTG variability in the former overlapping the expected RTG of the latter [17$19,119]$. The RTG seems to be increased in patients with $\mathrm{T} 2 \mathrm{D}$, especially in the elderly and those with long diabetes duration and higher body mass index [19]. In these patients, supposed to be the best candidates for SGLT2 inhibition because of their high RTG, the damaged kidney structure and its reduced function may impair the expected glycosuric response. In fact, a better SGLT2i effect is observed in younger diabetic patients [28].

The few studies carried out in kidneys from T2D patients reported decreased [70] or unchanged [68] GLUT1 mRNA levels while GLUT2 mRNA was described as reduced [68] or raised [100]. In exfoliated PT cells, isolated from the urine of T2D patients and cultured in a hyperglycaemic environment, GLUT2 and SGLT2 protein and mRNA were increased compared to healthy controls [69].

In diabetic patients, SGLT1 mRNA levels in tissues from biopsies $[68,100]$ or nephrectomies [70] were unchanged $[70,100]$ or raised [68] without any data about protein levels. Regarding SGLT2, its mRNA levels were described as increased $[100]$ or reduced $[68,70]$ while increased protein content was reported [100]. These very conflicting results can be explained by methodological differences in tissue collection and storage, diabetic status, and possible kidney abnormalities of the control group.

3.2.4. Glucose Effects on Renal Glucose Transporters. In animal models, plasma and luminal glucose concentrations have been shown to stimulate GLUT2 expression $[26,120]$ and, even, to translocate the transporter from basolateral to BBM side [26]. In canine PT polarized cultures with apical and basolateral cell layers, GLUT2 migrated to the apical side exposed to isolated glucose stimulus [20].

Both SGLTs also seem to be under glucose influence. In cultures of human embryonic kidney (HEK) cells, glucose promoted trafficking of SGLT1 proteins to plasma membrane without changes in the total pool [23] but did not change SGLT1 mRNA levels in PT cultured human kidney2 (HK2) cells [22]. In addition, glucose stimulated SGLT2 mRNA transcription and amplified SGLT2 protein pool in cultures of human PT cells [22] and promoted its translocation from the intracellular compartment to the membrane in HEK cell cultures [21]. One study, on the other hand, reported a neutral glucose effect on SGLT2 content and/or activity in cultures of human PT cells [121].

3.2.5. Insulin Effect on Renal Glucose Transport. Insulin effects on cells and tissue metabolism result from a highly integrated network of different pathways [122]. IRecs on cell surface, after the insulin binding, phosphorylate the insulin receptor substrate proteins (IRS) that, in turn, activate two main signalling pathways: the phosphatidylinositol 3-kinase (PI3K)/protein kinase B (AKT) pathway, which regulates the majority of insulin metabolic effects, and the Rasmitogen-activated protein kinase (MAPK) pathway. MAPK participates in the control of cell growth and differentiation through gene expression regulation [122-124]. Insulin itself is the utmost inhibitor of its own signalling [123].

In 1951, Farber at al. demonstrated that insulin decreased Tmax in diabetic patients but under very high insulin plasma levels [48]. However, in a recent trial, physiological insulin levels increased urinary glucose excretion under hyperglycaemic conditions in healthy but not in diabetic volunteers [125]. Both studies separated the insulin effect from glycaemic variation. Thus, emerging questions are as follows: in which way is the higher Tmax of diabetic patients related to insulin resistance, hyperinsulinaemia, or insulin deficiency; and which are the relationships between the insulin signalling and PTs glucose transport proteins activity. That provides a rationale to investigate an insulin effect, isolated or combined to glucose and insulin resistance, on glucose transport proteins, mainly on their function.

Assessing insulin action by itself, a dual temporal insulin effect on glucose uptake was reported in murine PT cultures: raised in the first twenty minutes and returning to the initial rate after thirty minutes [49]. In these cultures, insulin increased GLUT1 mRNA and membrane protein contents but other glucose transporters were not evaluated. Accordingly, regulatory proteins involved in pathways triggered by insulin upregulates the cell surface GLUT1 expression in HEK cell cultures [126]. GLUT1 traffic to the apical membrane in HEK cells has been demonstrated under PI3K/AKT signalling with elevated glucose uptake [127]. The AKT signalling interacts with megalin and the AKT substrate of $160 \mathrm{kDa}$ (AS160), the most downstream insulin signalling step related to insulin-stimulated glucose transport [126, 128]. This signalling reproduces the same insulin-dependent GLUT4 traffic demonstrated in adipocytes [129] and myocytes [130] and could justify GLUT1 raising in HEK and PT cultures exposed to insulin. Concerning renal GLUT2 expression, it was elevated in the presence of insulin resistance, visceral obesity, high triglycerides, and low high-density lipoprotein cholesterol concentrations even under normal glucose levels, in Otsuka Long-Evans Tokushima Fatty (OLETF) rats [25], a T2D model.

About the SGLT system, insulin seems to regulate SGLT1 directly [21] and indirectly [131, 132]. In HEK cell cultures, two hours of insulin exposition inhibited SGLT1 activity [21]. In contrast, the serum and glucocorticoid inducible kinase (SGK1), which is activated by both glucose [133] and insulin [131], stimulated SGLT1 function [132]. The reported findings are very important since the SGLT1 system is virtually fully activated after SGLT2i use or in high glycaemic levels as in diabetes. Besides, SGLT1 is the predominant BBM glucose transporter at PT S3 portion $[63,64]$, the nephron site with the highest IRec level (46).

Experimental studies indicate SGLT2 activation by insulin. In fact, IRecs seem to be required for maximal SGLT2 expression and SGLT2-mediated glucose reabsorption as evidenced by studies in mice knockout for renal tubule-specific IRecs [134]. Insulin also raised the SGLT2 activity $[21,121]$ and protein levels [121] independently 
of glucose concentrations in cultures of human kidney cells. In HEK cells, insulin increased SGLT2 glucose transport by 200 to $300 \%$, probably by stimulating the SGLT2 translocation from an intracellular pool to the S1 and S2 BBM segments [21]. A similar finding was reported using cultured human PT cells where insulin increased SGLT2 content and/or activity in a dose-dependent response [121]. However, in $\mathrm{HK} 2$ cells, the activation of the liver $\mathrm{X}$ receptor decreases SGLT2 protein and its function. The liver X receptor is a nuclear receptor family that plays a major role in energy metabolism and regulates several membrane transporters. As insulin activates liver X receptor, it could indirectly decrease SGLT2 content [135]. Furthermore, in an Alloxan T1D rat model, insulin reduced SGLT2 mRNA independently of glucose levels [112]. Despite the conflicting data, all these findings open the possibility that the higher SGLT2 levels in diabetic states can be attributed not only to elevated glycaemic concentrations but also to a direct or indirect insulin action. Moreover, insulin resistance perhaps modulates SGLT availability and activity, but this issue was not well evaluated until now.

As insulin resistance is associated with an imbalance of the autonomic system, insulin could indirectly modulate the RTG and Tmax through sympathetic system stimulation. In fact, the reduction of renal sympathetic activity limits SGLT2 excessive transcription in rat models enhancing urinary glucose excretion [22] as well as reducing renal gluconeogenesis in pigs [136].

Organic anion transporters (OAT), proteins situated in the basal membrane of PT cells, contribute to cellular uptake and secretion of multiple molecules to the luminal side, including the SGLT2 inhibitors [137, 138]. The SGLT2i action is related to the SGLTi luminal concentration reached in the S1 and S2 portions and thus depends primarily on the glomerular filtration [139]. However, tubular secretion of SGLT2i [140] mediated by OAT proteins increases its tubular concentration and action [137]. OAT type 3 (OAT3), through its colocalization with SGLT2 but not with SGLT1, enhanced the empagliflozin glycosuric effect [140]. The insulin effect raising [141] and the insulin resistance decreasing [142] renal OAT3 activity on the renal cortex suggest a link between insulin action and pharmacological inhibition of SGLT2. Indeed, a better understanding of insulin effects on tubular glucose transport and its interaction with SGLTi is imperative.

3.2.6. $\mathrm{Na}^{+} \mathrm{K}^{+}$ATPase (NKA). The ubiquitous NKA protein and its activity have been intensively studied for some decades before our review interval. This transporter is under the influence of many factors, including glucose, catecholamines, C-peptide, insulin, and other hormones [143, 144]. The insulin effect on NKA activity is cell type-specific and depends on the time and intensity of exposition displaying acute and chronic responses $[144,145]$.

NKA maintains a sodium gradient across the basolateral membrane of PT cells that provides the driving force for the SGLT activity [146]. In this way, changes in NKA activity presumably have an impact on SGLT function and glucose recovery. As insulin influences NKA function and that function directly modulates the SGLT glucose uptake, to evaluate the NKA activity in diabetes can give important information concerning the mechanisms of renal glucose handling regulation by insulin.

Old studies in diabetes models evaluated the NKA activity in the whole kidney and nephron segments, but not in isolated PTs [147], and were inconclusive. Results of recent studies in the whole kidney are still contradictory [148-154] probably because of mixed tissue responses and discrepancies in disease duration and glucose levels.

In the renal cortex of murine STZ models, NKA activity was reported as increased [155-157] or as reduced due to impaired insulin binding to its receptor [158]. In two of those reports with increased NKA activity, insulin treatment reduced it $[155,157]$. The duration of disease, i.e., sustained hyperglycaemia or chronic adaptation to it, could have contributed to the differences, as in one study diabetes lasted twice as long as in the other. A specific study on PTs of T2D rats showed a raised NKA activity [159]. In any case, none of these studies investigated the insulin and glucose effects separately.

Although these do not fully represent the real in vivo process, cell culture studies evaluating isolated insulin and glucose effects can give a better understanding of the interaction between NKA activity and insulin signalling. Glucose reduced NKA membrane protein and its activity in cultured tubular cells from human nephrectomies [143], and an indirect effect of glucose was demonstrated in HK2 cell cultures where advanced glycation end products reduced NKA activity $[160,161]$. An inhibitory glucose effect was also demonstrated in cell cultures of proximal tubule lines from porcine kidneys (LLC-PK1) associated with a downregulation of the surface expression $\alpha 1$ subunit, the NKA active site $[162,163]$. Thus, glucose seems to be a negative regulator of its own uptake.

Regarding insulin, a short exposition to it (until 30 minutes) raised NKA activity [160,161, 164], whereas exposition for more than 24 hours reduced NKA activity in rat PT cultures [165]. In the same way, in a culture complex model, insulin exposition raised renal NKA activity in the first 30 minutes, but it returned to the baseline levels after 2 hours and was even lower at 48-hour measurements [166]. This reduction was likewise observed after one hour of insulin exposition in another study [167]. Taken together, these results suggest a dual temporal insulin action on NKA activity. In the NKA low activity second phase, insulin could limit SGLT function by reducing the sodium gradient across the BBM. However, once glucose impacts NKA activity too, the described limiting insulin effect should be evaluated also in the presence of variable and elevated glucose levels, as in diabetes states. Besides, it should be assessed considering a possible renal insulin resistance.

C-peptide is another reported NKA modulator of interest. It increased NKA activity in cultures of human tubular cells from nondiabetic patients [143] and increased NKA alpha subunit mRNA in the renal cortex from STZ rats [168].

3.3. Insulin Regulation of Renal Gluconeogenesis. Another important insulin action on PTs is gluconeogenesis inhibition. Liver and renal cortical cells, primarily the PTs [3], are 
classical tissues that have the enzymatic apparatus necessary to significantly release glucose into the circulation. Hence, PTs contribute to the total endogenous glucose production in fasting and even in postprandial states [47]. Renal glucose release under normal conditions is about 20 to $25 \%$ of total systemic glucose production in fasting and $60 \%$ in the postprandial state [169].

As kidneys are not able to store significant amounts of glycogen and as glycogenolysis enzymes are lacking, the renal glucose production is provided basically by gluconeogenesis that generates $15-55 \mathrm{~g}$ of glucose and kidneys metabolize $25-35 \mathrm{~g}$ of glucose per day [47, 170]. Insulin suppresses the renal gluconeogenesis to a lesser extent than it does in the liver probably because of the lower kidney sensitivity to this insulin effect. However, such a difference could be the result of lower insulin delivery to the renal tissue. Furthermore, glucagon has little to no effect on renal gluconeogenesis [170-172]; hence, catecholamines are the major counter regulator of insulin-induced inhibition of gluconeogenesis in the kidneys [170, 172].

Renal gluconeogenesis is enhanced in STZ rats $[4,14,46$, $67,110,173]$, in murine model knockout for IRecs [174] or IRS1 plus IRS2 [4], in a mix model of high-fat diet plus STZ [175], and in T2D murine models [176, 177] demonstrating the essential insulin role.

Reabsorbed glucose from tubular filtrate $[4,178]$ and insulin [4] seems to have a complementary inhibitory effect on renal gluconeogenesis. In fact, the higher postprandial insulin levels reduce PT gluconeogenic enzyme transcription in wild mice [4] and rabbits [179], and gluconeogenic gene expression was reduced by the glucose counterregulatory effect in insulin-resistant and insulinopenic models [4]. In addition, SGLT1 plus SGLT2 inhibition by phlorizin restored gluconeogenic activity in these models [4] and isolated SGLT2 inhibition in normal mice activated renal gluconeogenic gene expression [178]. Therefore, the reduction of glucose flux across PT cells stimulates gluconeogenesis. Moreover, in HK2 cell cultures, insulin and glucose inhibit gluconeogenic enzymes across distinct pathways [4].

In accordance, PT cells from human nephrectomies [176] and HK2 cell cultures [4] exposed to insulin undergo gluconeogenesis reduction. However, a high gluconeogenic enzyme content in human renal biopsies from T2D was reported [46] which could be interpreted as an impairment of insulin action on kidneys, maybe a kidney-specific insulin resistance. The intracellular glucose generated from highintensity gluconeogenesis might impact the glucose transport through modifications of SGLT2 transcription or its pool mobilization, as described for the extracellular glucose stimulus in PT cells of diabetes models. That could mean an additional indirect insulin regulation of glucose transport, in this case, through gluconeogenesis.

3.4. Renal Insulin Resistance. Despite the higher Tmax for glucose in diabetic patients compared to healthy subjects, it is not clear if renal insulin resistance could impact glucose transport. Even the concept of renal insulin resistance is still debatable. Insulin resistance, in general, is characterized by an attenuation of its triggered biologic processes inducing metabolic impairment $[123,180,181]$, and the insulin resistance phenotype is variable among organs and even among tissues from the same organ. For example, the liver has selective insulin resistance, and metabolic pathways diverge according to specific spatial zonation near or distal to the portal space [123]. The same may be possible in different renal segments according to the presence and density of IRecs and insulin availability considering the hormone filtration, extraction, and degradation.

The variability of protein isoforms of the insulin signalling cascade (IRecs, IRS, PI3K, and AKT) [122] and of diabetes phenotypes, mainly in T2D $[182,183]$, is partially due to genetic variations [184-186] and may be related to specific tissue resistance differences. In addition, insulin signalling determines several phenotypic characteristics regarding cell size and proliferation in PTs [187]. Therefore, another question is if the insulin action on PT glucose transport is impaired in insulin resistance.

The two IRec isoforms differ in affinity to insulin binding and metabolic effects $[188,189]$. In humans, IRec type B, available mainly in insulin-sensitive organs (skeletal muscle, liver, and adipose tissue) $[188,190]$, is abundant in kidneys too [190]. In rat models, insulin binding [50] and IRecs are present along the whole nephron with the highest levels at PTs, especially in the outer medullary S3 portion [46]. The distal convoluted tubule is another nephron segment where insulin binding is high [50] and where insulin stimulates sodium reabsorption $[180,191,192]$. At PTs, insulin stimulates sodium uptake also through $\mathrm{Na}^{+} \mathrm{H}^{+}$exchanger type 3 (NHE3) [180].

The differences in IRec density and of insulin concentration along the nephron indicate a specific site and variable hormone action. Some findings in animal cell cultures demonstrated variations of nephron or PT IRec densities. In PTs of normal rats, IRecs are localized in the basolateral membrane where it may sense insulin from capillaries while IRec on the apical membrane is involved in insulin reabsorption $[44,46]$. IRecs accumulate into the cytoplasm during fasting and in the two membranes after refeeding consequent to both insulin and glucose oscillations [46]. Insulin decreases its own receptors in murine PT cultured cells [165]. Reduced IRec protein expression in all nephron segments in either insulin-resistant [193] or insulinopenic rats [46] has been described. The latter had a stronger reduction in the renal cortex and distal tubules [46]. The increase of membrane IRecs after feeding was also lost in diabetes models [46]. In humans, IRec protein expression was also significantly reduced in renal biopsies from T2D patients with a pronounced downregulation observed in PTs and slightly in distal tubule cells [46] again suggesting reduced insulin action on PTs.

Impairment of another step of the insulin signalling cascade in PTs has been described. After the IRS phosphorylation triggered by the insulin binding, the IRS tyrosine residues serve as anchoring sites for regulatory subunits of PI3K at the cell membrane cytoplasmic side [194]. The IRS1 and IRS2 isoforms, widely expressed in human tissues, have distinct physiological roles in vivo [33] and are frequently decreased in insulin-resistant states [124]. Hyperinsulinaemia 
induces IRS1 and IRS2 protein degradation [195] across different pathways [124], according to the target organ where the insulin resistance takes place. In PTs of insulin-resistant murine models, the stimulatory effect of insulin via IRS1 is impaired in contrast to a preserved IRS2 insulin signalling [180]. IRS2 has a role in PT sodium transport not related to the SGLT system $[121,196]$. On the other hand, IRS1 impaired signalling may be associated with a lesser inhibition of renal gluconeogenesis $[46,47,197]$. While IRS1 expression and phosphorylation are normal [198] or reduced [199], IRS2 has normal levels in diabetes models [27, 191]. IRS2 expression is preserved in the renal cortex of insulinresistant patients [191] or even enhanced in tubules of patients with diabetic nephropathy [200]. These findings corroborate the renal insulin resistance hypothesis as well as a site-specific and selective resistance. It is reasonable that a PT insulin resistance, beyond being related to an impaired gluconeogenesis regulation, could impact renal glucose transport and thus hypothetically contribute to the higher Tmax found in diabetes.

Other corroborating evidences are the increased inflammatory markers (NF- $\kappa \mathrm{B}, \mathrm{TNF} \alpha$, IL-6, and IL-10) reported in cortical tissues of murine diabetes models [201-203], HK2 cell cultures under high glucose environment (NF- $\kappa \mathrm{B}$ ) [204], and cortical portions of T2D patients (NF- $\kappa$ B) [202]. These elevated markers were associated with disrupted insulin signalling characterized by high FOXO1 and reduced AKT [202], PPAR $\gamma$, and ISRS1 [201, 203] but maintained ISR2 levels [201]. Increased renal gluconeogenesis [202], as expected, and reduced GLUT2 [203] were also associated with enhanced inflammatory markers.

\section{Summary of Evidence and Discussion}

The review objective was to describe and summarize the literature data about the insulin effect on renal glucose transport. We aimed to construct a sequence of evidence to facilitate the reader access to the current understanding of insulin action on renal proximal tubules, the nephron site responsible for the glucose uptake from glomerular filtrate, and where renal gluconeogenesis takes place. In the following paragraphs, the main findings are summarized.

Kidneys, mainly PTs, play a significant role in insulin metabolism. Insulin upregulates its own PT uptake and degradation [41], thus changing insulin availability in the whole body and specific renal sites $[54,55]$.

Regarding glucose transporters in diabetes, T1D models showed increased GLUT1 protein availability and mRNA expression in the whole kidney and higher cortical GLUT1 mRNA expression. These changes can be transitory and site-specific. Results concerning GLUT2 are controversial. SGLT1 studies agreed only in the upregulation of its mRNA expression in T2D models while protein and mRNA SGLT2 contents in both T1D and T2D models are frequently reported as increased (Table 1). Elevated SGLT2 levels could explain the higher glucose uptake capacity of diabetic patients. Human studies, however, are scarce and contradictory with few studies demonstrating raised SGLT2 protein availability in diabetic patients.
Insulin alone $[21,121]$ or with glucose $[24,25]$ can modulate availability and/or function of PT glucose transporters beyond changing renal gluconeogenesis $[4,178]$. The insulin effect in murine PT cell cultures seems to increase GLUT1 content and trafficking $[49,126]$. Insulin resistance, on the other hand, is associated with increased GLUT2 in animal models [25] while insulin replacement reduces this transporter availability [24]. However, glucose level variations may have confused the results in these models. While glucose has promoted SGLT1 trafficking [23], insulin seems to directly inhibit the SGLT1 activity in renal human cell cultures [21] but could activate it indirectly [131]. Furthermore, glucose seems to amplify membrane SGLT2 protein availability in these cultures [22]. It was reported that insulin raises SGLT2 protein availability and activity independently of glucose and additionally regulates SGLT2i bioavailability [140-142]. Differences in IRec density along the nephron [46] and in the type of IRS expressed in diverse tubule segments, or the same segment but under distinct insulin sensitivity [27, 191, 199-201, 203], point to a renal site-specific selective insulin action and, possibly, to a spatial selective insulin resistance.

Insulin action on the sympathetic system can, indirectly, modulate SGLT2, hence changing glucose handling [22]. In addition, renal gluconeogenesis is enhanced in diabetes $[4,14,46,67,110,173-177]$ and is inhibited by insulin $[4,179]$, which could influence glucose reabsorption through SGLT2 [21, 22].

NKA activity might impact SGLTs by providing the driving force for their activity [146]. In murine models of diabetes, changes in NKA function are probably due to high glycaemic levels [155-157, 159] and impaired insulin signalling [158]. Nevertheless, the results' heterogeneity does not allow to clearly define the insulin effect on NKA. In complex models of animal PT cultures, NKA activity increased after short exposition to insulin but decreased under sustained stimulus [160, 161, 164-167]. In human tubular cell cultures, glucose inhibited while C-peptide stimulated NKA activity $[143,168]$.

All of the above findings are summarized in Figures 2(a) and 2(b).

Therefore, the elevated Tmax of diabetic patients [16, $18,19,48,118$ ] yet so far not completely known is possibly associated with an upregulation of glucose protein transporters and may be related to insulin in many ways. Human studies with reproducible and comparable methodology are needed to understand the real impact of insulin on glucose transport in healthy and diabetic subjects, independently of glucose influence.

Our review has limitations. It is circumscribed to publications in the last 10 years. The literature search using specific terms and the limitation to publications in English may have missed some papers related to our aim. Other difficulties are related to the issue itself. In fact, most studies did not have the insulin action on glucose transport as their first objective. Results are not always comparable taking into account differences among species [102, 189, 205] and study models. In human studies, one limitation is the inclusion of subjects with other kidney diseases as the control group rather than 


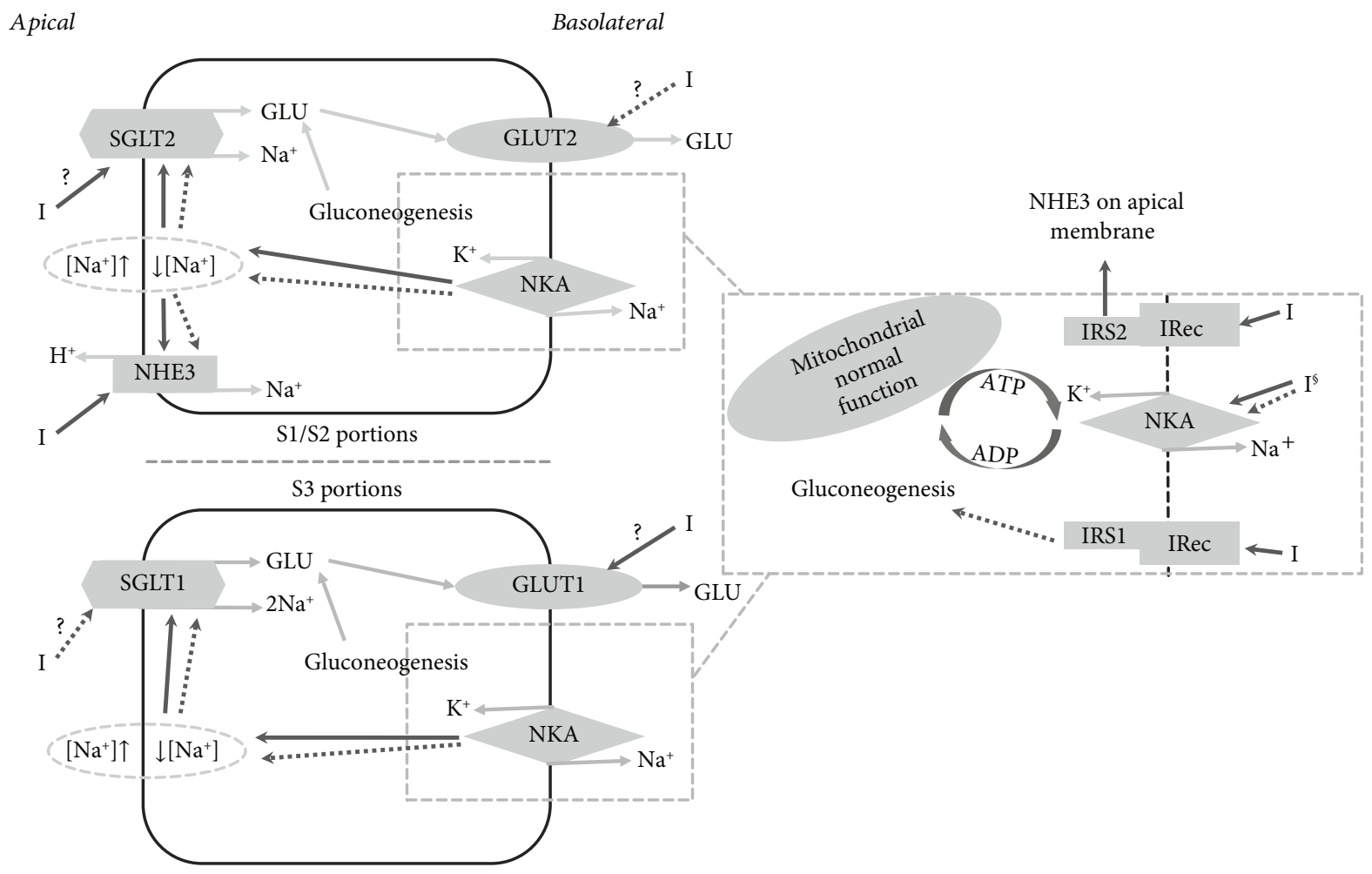

(a)

Apical Basolateral

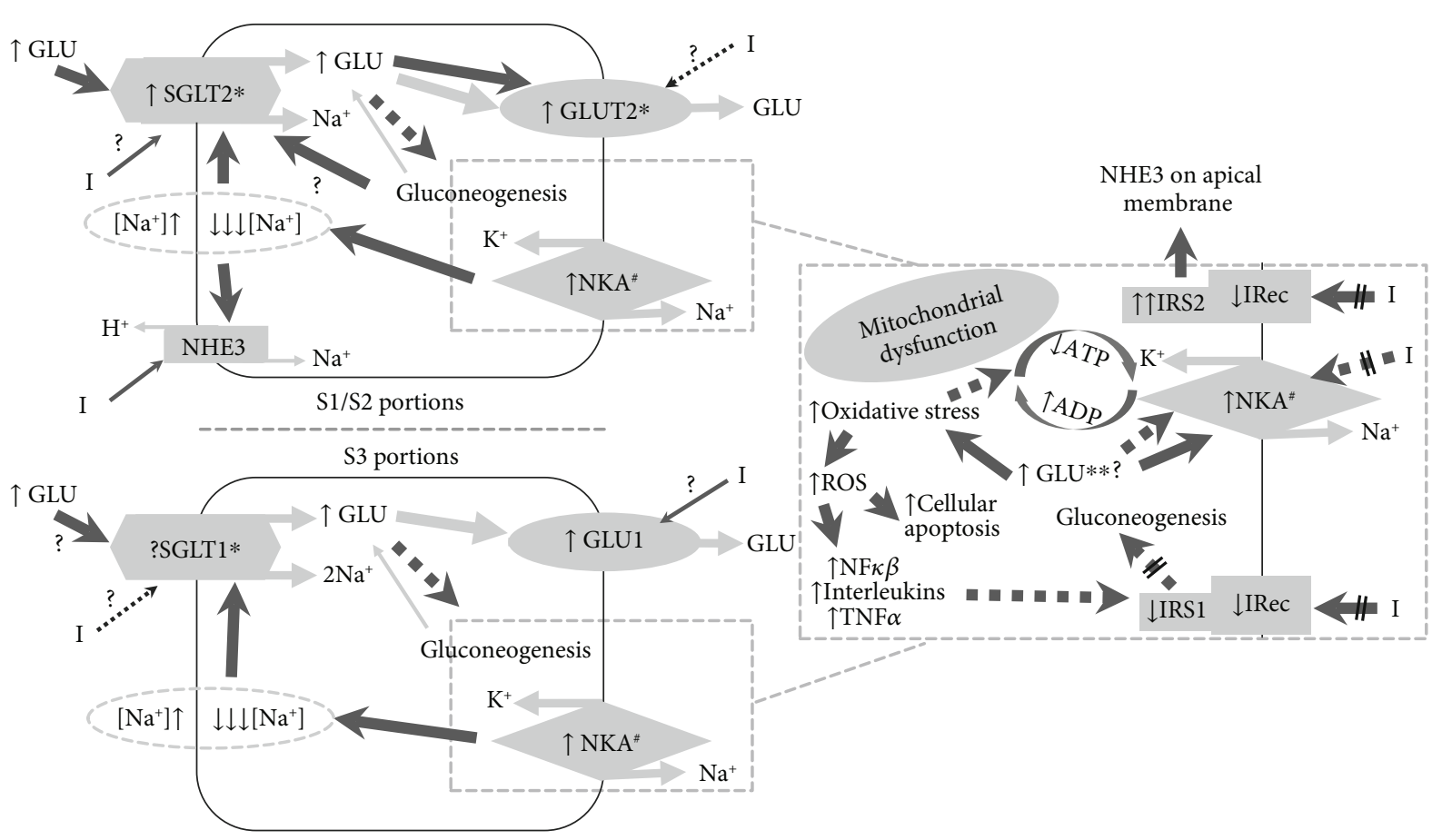

(b)

FIGURE 2: (a) Insulin effect on renal proximal tubule cells. (b) Diabetes, hyperinsulinaemia, and insulin resistance impact on renal proximal tubule cells. Grey arrows = flux; black continuous arrows=stimulatory effect; black interrupted arrows=inhibitory effect; thicker arrows = increased activity. I: insulin; GLU: glucose; ROS: reactive oxygen species; NHE3: $\mathrm{Na}^{+} \mathrm{H}^{+}$exchanger type 3; NKA: Na ${ }^{+} \mathrm{ATPase}^{+}$ IRecs: insulin receptors; IRS: insulin receptor substrate proteins; NF- $\kappa$ B: nuclear factor kappa-light-chain-enhancer of activated B cells; TNF $\alpha$ : tumor necrosis factor alpha; IL-6 and IL-10: interleukins. "Scanty or conflicting data; "reduced effect; *enhanced in animal models but conflicting human data; $* *$ enhanced in murine models but reduced in cultures; ${ }^{5}$ temporal dual action according to exposition (short time $=$ stimulatory and sustained $=$ inhibitory); ${ }^{*}$ total NKA function increased despite inhibitory GLU effect and mitochondrial dysfunction. 
just healthy ones. Moreover, frequently, insulin and glucose effects were not evaluated separately. Cell culture models are able to isolate these effects although they do not consider the microenvironment of the whole organ, possibly influencing transcriptional regulators of genes involved in glucose utilization $[49,206]$, and do not consider the hormonal [49, 207-209] and neural [22, 209] crosstalking among organs. It is still important to take into account that mRNA or protein measurements do not necessarily reflect their dynamic function. At the same protein content, its function can be enhanced or diminished by modification of serum lipids and fluidity in the cytoplasmic membrane [144], by transporter conformational changes [5] or by subcellular spatial arrangement $[67,210]$. Furthermore, protein interactions in the cytoplasmic membrane side, as described for SGLT2 and its anchoring protein [211], can be related to variation in glucose transporter function without any change in the protein content $[210,212]$.

In conclusion, the upregulation of renal glucose transporters, mainly SGLT2, associated with sustained hyperglycaemia, or to a disrupted renal insulin signalling, can be related to the increased maximum renal glucose reabsorptive capacity observed in diabetes. The several effects of insulin on distinct kidney sites can modify glucose transport directly, through changes of glucose transporter availability and function, or indirectly through $\mathrm{Na}^{+} \mathrm{K}^{+} \mathrm{ATPase}$ activity modulation. Thus, there is evidence of insulin effect not only on renal gluconeogenesis but also on renal glucose transport. However, until now the scarcity and the heterogeneity of the studies limit an accurate proposal of the implicated mechanisms.

\section{Abbreviations}

AKT: $\quad$ Protein kinase B

BBM: Brush border membrane

GLUT: Facilitative glucose transporter

HEK: Human embryonic kidney

HK2: Human kidney-2

IRecs: Insulin receptors

IRS: Insulin receptor substrate proteins

NKA: $\quad \mathrm{Na}^{+} \mathrm{K}^{+}$ATPase

PI3K: Phosphatidylinositol 3-kinase

PTs: $\quad$ Proximal tubules

S1 PTs: Proximal segment

S2 PTs: Intermediary segment

S3 PTs: Distal segment

SGLT: Sodium-glucose linked transporter

SGLT2i: SGLT2 inhibitors

STZ: Streptozotocin

RTG: Renal threshold for glucose

T1D: $\quad$ Type 1 diabetes

T2D: $\quad$ Type 2 diabetes

Tmax: Maximum renal glucose reabsorptive capacity.

\section{Conflicts of Interest}

The authors declare no conflict of interest regarding the publication of this paper.

\section{Authors' Contributions}

RP-M and EM designed the research. RP-M performed the article search. Both authors selected the articles. RP-M performed the data extraction and EM reviewed it. Both authors wrote, revised, and discussed the manuscript.

\section{References}

[1] World Health Organization, Global report on diabetes, World Health Organization, 2016.

[2] R. Rabkin, M. P. Ryan, and W. C. Duckworth, "The renal metabolism of insulin," Diabetologia, vol. 27, no. 3, pp. 351-357, 1984.

[3] M. P. Benoy and K. A. Elliott, "The metabolism of lactic and pyruvic acids in normal and tumour tissues: synthesis of carbohydrate," The Biochemical Journal, vol. 31, no. 8, pp. 12681275, 1937.

[4] M. Sasaki, T. Sasako, N. Kubota et al., "Dual regulation of gluconeogenesis by insulin and glucose in the proximal tubules of the kidney," Diabetes, vol. 66, no. 9, pp. 2339-2350, 2017.

[5] E. M. Wright, D. D. F. Loo, and B. A. Hirayama, "Biology of human sodium glucose transporters," Physiological Reviews, vol. 91, no. 2, pp. 733-794, 2011.

[6] A. Sarashina, K. Ueki, T. Sasaki et al., "Effect of renal impairment on the pharmacokinetics, pharmacodynamics, and safety of empagliflozin, a sodium glucose cotransporter 2 inhibitor, in Japanese patients with type 2 diabetes mellitus," Clinical Therapeutics, vol. 36, no. 11, pp. 1606-1615, 2014.

[7] M. W. Taal, G. M. Chertow, P. A. Marsden, K. Skorecki, S. L. Alan, and B. M. Brenner, Brenner and Rector's The Kidney EBook, Elsevier Health Sciences, 2011.

[8] M. Carlström, C. S. Wilcox, and W. J. Arendshorst, "Renal autoregulation in health and disease," Physiological Reviews, vol. 95, no. 2, pp. 405-511, 2015.

[9] M. W. Brands and M. M. Manhiani, "Sodium-retaining effect of insulin in diabetes," American Journal of Physiology - Regulatory, Integrative and Comparative Physiology, vol. 303, no. 11, pp. R1101-R1109, 2012.

[10] B. J. Tucker, C. M. Anderson, R. S. Thies, R. C. Collins, and R. C. Blantz, "Glomerular hemodynamic alterations during acute hyperinsulinemia in normal and diabetic rats," Kidney International, vol. 42, no. 5, pp. 1160-1168, 1992.

[11] N. Naderpoor, J. G. Lyons, A. Mousa et al., "Higher glomerular filtration rate is related to insulin resistance but not to obesity in a predominantly obese non-diabetic cohort," Scientific Reports, vol. 7, no. 1, 2017.

[12] E. Cersosimo, P. Garlick, and J. Ferretti, "Insulin regulation of renal glucose metabolism in humans," The American Journal of Physiology - Endocrinology and Metabolism, vol. 276, no. 1, pp. E78-E84, 1999.

[13] C. Meyer, J. M. Dostou, S. L. Welle, and J. E. Gerich, "Role of human liver, kidney, and skeletal muscle in postprandial glucose homeostasis," The American Journal of Physiology Endocrinology and Metabolism, vol. 282, no. 2, pp. E419E427, 2002.

[14] S. N. Patel, M. Parikh, and C. A. Lau-Cam, "Impact of light ethanol intake and of taurine, separately and together, on pathways of glucose metabolism in the kidney of diabetic rats," Taurine 9, vol. 803, pp. 279-303, 2015. 
[15] H. Al-Jobori, G. Daniele, E. Cersosimo et al., "Empagliflozin and kinetics of renal glucose transport in healthy individuals and individuals with type 2 diabetes," Diabetes, vol. 66, no. 7, pp. 1999-2006, 2017.

[16] R. A. DeFronzo, M. Hompesch, S. Kasichayanula et al., "Characterization of renal glucose reabsorption in response to dapagliflozin in healthy subjects and subjects with type 2 diabetes," Diabetes Care, vol. 36, no. 10, pp. 3169-3176, 2013.

[17] K. Rave, L. Nosek, J. Posner, T. Heise, K. Roggen, and E. J. van Hoogdalem, "Renal glucose excretion as a function of blood glucose concentration in subjects with type 2 diabetes-results of a hyperglycaemic glucose clamp study," Nephrology, Dialysis, Transplantation, vol. 21, no. 8, pp. 2166-2171, 2006.

[18] B. Ruhnau, O. K. Faber, K. Borch-Johnsen, and B. Thorsteinsson, "Renal threshold for glucose in noninsulin-dependent diabetic patients," Diabetes Research and Clinical Practice, vol. 36, no. 1, pp. 27-33, 1997.

[19] X. D. Yue, J. Y. Wang, X. R. Zhang et al., "Characteristics and impact factors of renal threshold for glucose excretion in patients with type 2 diabetes mellitus," Journal of Korean Medical Science, vol. 32, no. 4, pp. 621-627, 2017.

[20] M. Cohen, D. Kitsberg, S. Tsytkin, M. Shulman, B. Aroeti, and Y. Nahmias, "Live imaging of GLUT2 glucosedependent trafficking and its inhibition in polarized epithelial cysts," Open Biology, vol. 4, no. 7, p. 140091, 2014.

[21] C. Ghezzi and E. M. Wright, "Regulation of the human Na +-dependent glucose cotransporter hSGLT2," American Journal of Physiology-Cell Physiology, vol. 303, no. 3, pp. C348-C354, 2012.

[22] K. Rafiq, Y. Fujisawa, S. J. Sherajee et al., "Role of the renal sympathetic nerve in renal glucose metabolism during the development of type 2 diabetes in rats," Diabetologia, vol. 58, no. 12, pp. 2885-2898, 2015.

[23] O. Beloto-Silva, U. F. Machado, and M. Oliveira-Souza, "Glucose-induced regulation of NHEs activity and SGLTs expression involves the PKA signaling pathway," The Journal of Membrane Biology, vol. 239, no. 3, pp. 157-165, 2011.

[24] E. Chin, A. M. Zamah, D. Landau et al., "Changes in facilitative glucose transporter messenger ribonucleic acid levels in the diabetic rat kidney," Endocrinology, vol. 138, no. 3, pp. 1267-1275, 1997.

[25] A. Lehnen, N. Leguisamo, L. Dias et al., "Changes in renal glucose transporters in an animal model of metabolic syndrome," Hormone and Metabolic Research, vol. 45, no. 11, pp. 840-843, 2013.

[26] J. Marks, N. J. C. Carvou, E. S. Debnam, S. K. Srai, and R. J. Unwin, "Diabetes increases facilitative glucose uptake and GLUT2 expression at the rat proximal tubule brush border membrane," The Journal of Physiology, vol. 553, no. 1, pp. 137-145, 2003.

[27] K. Kitada, D. Nakano, H. Ohsaki et al., "Hyperglycemia causes cellular senescence via a SGLT2- and p21-dependent pathway in proximal tubules in the early stage of diabetic nephropathy," Journal of Diabetes and its Complications, vol. 28, no. 5, pp. 604-611, 2014.

[28] Y. Nakamura, Y. Nagai, Y. Terashima et al., "Better response to the SGLT2 inhibitor dapagliflozin in young adults with type 2 diabetes," Expert Opinion on Pharmacotherapy, vol. 16, no. 17, pp. 2553-2559, 2015.

[29] S. Takagi, J. Li, Y. Takagaki et al., "Ipragliflozin improves mitochondrial abnormalities in renal tubules induced by a high-fat diet," Journal of Diabetes Investigation, vol. 9, no. 5, pp. 1025-1032, 2018.

[30] T. Hatanaka, D. Ogawa, H. Tachibana et al., "Inhibition of SGLT2 alleviates diabetic nephropathy by suppressing high glucose-induced oxidative stress in type 1 diabetic mice," Pharmacology Research \& Perspectives, vol. 4, no. 4, p. e00239, 2016.

[31] S. Maeda, T. Matsui, M. Takeuchi, and S. Yamagishi, "Sodium-glucose cotransporter 2-mediated oxidative stress augments advanced glycation end products-induced tubular cell apoptosis," Diabetes/Metabolism Research and Reviews, vol. 29, no. 5, pp. 406-412, 2013.

[32] H. Osorio, I. Coronel, A. Arellano, M. Franco, B. Escalante, and R. Bautista, "Ursodeoxycholic acid decreases sodiumglucose cotransporter (SGLT2) expression and oxidative stress in the kidney of diabetic rats," Diabetes Research and Clinical Practice, vol. 97, no. 2, pp. 276-282, 2012.

[33] Z. Cheng, Y. Tseng, and M. F. White, "Insulin signaling meets mitochondria in metabolism," Trends in Endocrinology and Metabolism, vol. 21, no. 10, pp. 589-598, 2010.

[34] F. G. Banting, C. H. Best, J. B. Collip, W. R. Campbell, and A. A. Fletcher, "Pancreatic extracts in the treatment of diabetes mellitus," Canadian Medical Association Journal, vol. 12, no. 3, pp. 141-146, 1922.

[35] American Diabetes Association, "8. Pharmacologic approaches to glycemic Treatment:Standards of medical care in diabetes-2018," Diabetes Care, vol. 41, Supplement 1, pp. S73-S85, 2018.

[36] W. C. Duckworth and A. E. Kitabchi, "Insulin metabolism and degradation," Endocrine Reviews, vol. 2, no. 2, pp. 210233, 1981.

[37] E. Ferrannini, J. Wahren, O. K. Faber, P. Felig, C. Binder, and R. A. DeFronzo, "Splanchnic and renal metabolism of insulin in human subjects: a dose-response study," The American Journal of Physiology - Endocrinology and Metabolism, vol. 244, no. 6, pp. E517-E527, 1983.

[38] P. Kolman, A. Pica, N. Carvou et al., "Insulin uptake across the luminal membrane of the rat proximal tubule in vivo and in vitro," The American Journal of Physiology - Renal Physiology, vol. 296, no. 5, pp. F1227-F1237, 2009.

[39] M. A. Bryniarski, B. M. Yee, I. Jaffri et al., "Increased megalin expression in early type 2 diabetes: role of insulin-signaling pathways," The American Journal of Physiology - Renal Physiology, vol. 315, no. 5, pp. F1191-F1207, 2018.

[40] R. A. Orlando, K. Rader, F. Authier et al., "Megalin is an endocytic receptor for insulin," Journal of the American Society of Nephrology, vol. 9, no. 10, pp. 1759-1766, 1998.

[41] M. Hosojima, H. Sato, K. Yamamoto et al., "Regulation of megalin expression in cultured proximal tubule cells by angiotensin II type $1 \mathrm{~A}$ receptor- and insulin-mediated signaling cross talk," Endocrinology, vol. 150, no. 2, pp. 871-878, 2009.

[42] S. Nielsen, "Sorting and recycling efficiency of apical insulin binding sites during endocytosis in proximal tubule cells," American Journal of Physiology-Cell Physiology, vol. 264, no. 4, pp. C810-C822, 1993.

[43] A. I. Katz and A. H. Rubenstein, "Metabolism of proinsulin, insulin, and C-peptide in the rat," The Journal of Clinical Investigation, vol. 52, no. 5, pp. 1113-1121, 1973.

[44] R. Rabkin, N. M. Simon, S. Steiner, and J. A. Colwell, "Effect of renal disease on renal uptake and excretion of insulin in 
man," New England Journal of Medicine, vol. 282, no. 4, pp. 182-187, 1970.

[45] A. H. Rubenstein, M. E. Mako, and D. L. Horwitz, "Insulin and the kidney," Nephron, vol. 15, no. 3-5, pp. 306-326, 1975.

[46] R. Gatica, R. Bertinat, P. Silva et al., "Altered expression and localization of insulin receptor in proximal tubule cells from human and rat diabetic kidney," Journal of Cellular Biochemistry, vol. 114, no. 3, pp. 639-649, 2013.

[47] J. E. Gerich, C. Meyer, H. J. Woerle, and M. Stumvoll, "Renal gluconeogenesis: its importance in human glucose homeostasis," Diabetes Care, vol. 24, no. 2, pp. 382-391, 2001.

[48] S. J. Farber, E. Y. Berger, and D. P. Earle, "Effect of diabetes and insulin of the maximum capacity of the renal tubules to reabsorb glucose," The Journal of Clinical Investigation, vol. 30, no. 2, pp. 125-129, 1951.

[49] Y. S. Kang, H. K. Song, M. H. Lee et al., "Visfatin is upregulated in type-2 diabetic rats and targets renal cells," Kidney International, vol. 78, no. 2, pp. 170-181, 2010.

[50] D. Butlen, S. Vadrot, S. Roseau, and F. Morel, "Insulin receptors along the rat nephron: [125I] insulin binding in microdissected glomeruli and tubules," Pflügers Archiv, vol. 412, no. 6, pp. 604-612, 1988.

[51] R. Nakamura, D. S. Emmanouel, and A. I. Katz, "Insulin binding sites in various segments of the rabbit nephron," Journal of Clinical Investigation, vol. 72, no. 1, pp. 388-392, 1983.

[52] F. Authier, B. I. Posner, and J. J. Bergeron, "Insulin-degrading enzyme," Clinical and Investigative Medicine, vol. 19, no. 3, pp. 149-160, 1996.

[53] L. Zhao, B. Teter, T. Morihara et al., "Insulin-degrading enzyme as a downstream target of insulin receptor signaling cascade: implications for Alzheimer's disease intervention," The Journal of Neuroscience, vol. 24, no. 49, pp. 1112011126, 2004.

[54] F. Li, J. Yang, V. A. M. Villar et al., "Loss of renal SNX5 results in impaired IDE activity and insulin resistance in mice," Diabetologia, vol. 61, no. 3, pp. 727-737, 2018.

[55] F. Li, J. Yang, J. E. Jones et al., "Sorting nexin 5 and dopamine D1 receptor regulate the expression of the insulin receptor in human renal proximal tubule cells," Endocrinology, vol. 156, no. 6, pp. 2211-2221, 2015.

[56] G. I. Bell, C. F. Burant, J. Takeda, and G. W. Gould, "Structure and function of mammalian facilitative sugar transporters," The Journal of Biological Chemistry, vol. 268, no. 26, pp. 19161-19164, 1993.

[57] I. Vrhovac, D. Balen Eror, D. Klessen et al., "Localizations of $\mathrm{Na}$--d-glucose cotransporters SGLT1 and SGLT2 in human kidney and of SGLT1 in human small intestine, liver, lung, and heart," Pflügers Archiv - European Journal of Physiology, vol. 467, no. 9, pp. 1881-1898, 2015.

[58] C. S. Hummel, C. Lu, D. D. F. Loo, B. A. Hirayama, A. A. Voss, and E. M. Wright, "Glucose transport by human renal $\mathrm{Na}+/ \mathrm{D}$-glucose cotransporters SGLT1 and SGLT2," American Journal of Physiology. Cell Physiology, vol. 300, no. 1, pp. C14-C21, 2011.

[59] K. Takata, T. Kasahara, M. Kasahara, O. Ezaki, and H. Hirano, "Localization of $\mathrm{Na}(+)$-dependent active type and erythrocyte/HepG2-type glucose transporters in rat kidney: immunofluorescence and immunogold study," The Journal of Histochemistry and Cytochemistry, vol. 39, no. 3, pp. 287-298, 1991.
[60] B. Thorens, H. F. Lodish, and D. Brown, "Differential localization of two glucose transporter isoforms in rat kidney," American Journal of Physiology-Cell Physiology, vol. 259, no. 2, pp. C286-C294, 1990.

[61] G. Wirthensohn and W. G. Guder, "Renal substrate metabolism,” Physiological Reviews, vol. 66, no. 2, pp. 469-497, 1986.

[62] S. C. Cramer, W. M. Pardridge, B. A. Hirayama, and E. M. Wright, "Colocalization of GLUT2 glucose transporter, sodium/glucose cotransporter, and -Glutamyl Transpeptidase in rat kidney with double-peroxidase immunocytochemistry," Diabetes, vol. 41, no. 6, pp. 766-770, 1992.

[63] D. Balen, M. Ljubojević, D. Breljak et al., "Revised immunolocalization of the $\mathrm{Na}+$-d-glucose cotransporter SGLT1 in rat organs with an improved antibody," American Journal of Physiology-Cell Physiology, vol. 295, no. 2, pp. C475C489, 2008.

[64] I. Sabolić, M. Škarica, V. Gorboulev et al., "Rat renal glucose transporter SGLT1 exhibits zonal distribution and androgendependent gender differences," The American Journal of Physiology - Renal Physiology, vol. 290, no. 4, pp. F913-F926, 2006.

[65] J. Chen, S. Williams, S. Ho et al., "Quantitative PCR tissue expression profiling of the human SGLT2 gene and related family members," Diabetes Therapy, vol. 1, no. 2, article 6, pp. 57-92, 2010.

[66] I. Sabolić, I. Vrhovac, D. B. Eror et al., "Expression of Na+-dglucose cotransporter SGLT2 in rodents is kidney-specific and exhibits sex and species differences," American Journal of Physiology-Cell Physiology, vol. 302, no. 8, pp. C1174C1188, 2012.

[67] A. Tojo, S. Hatakeyama, S. Kinugasa, and M. Nangaku, "Angiotensin receptor blocker telmisartan suppresses renal gluconeogenesis during starvation," Diabetes, Metabolic Syndrome and Obesity: Targets and Therapy, vol. 8, pp. 103-113, 2015.

[68] L. Norton, C. E. Shannon, M. Fourcaudot et al., "Sodium-glucose co-transporter (SGLT) and glucose transporter (GLUT) expression in the kidney of type 2 diabetic subjects," Diabetes, Obesity and Metabolism, vol. 19, no. 9, pp. 1322-1326, 2017.

[69] H. Rahmoune, P. W. Thompson, J. M. Ward, C. D. Smith, G. Hong, and J. Brown, "Glucose transporters in human renal proximal tubular cells isolated from the urine of patients with non-insulin-dependent diabetes," Diabetes, vol. 54, no. 12, pp. 3427-3434, 2005.

[70] A. Solini, C. Rossi, C. M. Mazzanti, A. Proietti, H. Koepsell, and E. Ferrannini, "Sodium-glucose co-transporter (SGLT)2 andSGLT1renal expression in patients with type 2 diabetes," Diabetes, Obesity and Metabolism, vol. 19, no. 9, pp. 12891294, 2017.

[71] R. A. DeFronzo, L. Norton, and M. Abdul-Ghani, "Renal, metabolic and cardiovascular considerations of SGLT2 inhibition," Nature Reviews Nephrology, vol. 13, no. 1, pp. 1126, 2017.

[72] K. Mitsuoka, Y. Hayashizaki, Y. Murakami et al., "Functional imaging of pharmacological action of SGLT2 inhibitor ipragliflozin via PET imaging using11C-MDG," Pharmacology Research \& Perspectives, vol. 4, no. 4, p. e00244, 2016.

[73] T. Rieg, T. Masuda, M. Gerasimova et al., "Increase in SGLT1-mediated transport explains renal glucose reabsorption during genetic and pharmacological SGLT2 inhibition in euglycemia," The American Journal of Physiology - Renal Physiology, vol. 306, no. 2, pp. F188-F193, 2014. 
[74] M. Sala-Rabanal, B. A. Hirayama, C. Ghezzi et al., "Revisiting the physiological roles of SGLTs and GLUTs using positron emission tomography in mice," The Journal of Physiology, vol. 594, no. 15, pp. 4425-4438, 2016.

[75] T. Heise, E. Seewaldt-Becker, S. Macha et al., "Safety, tolerability, pharmacokinetics and pharmacodynamics following 4 weeks' treatment with empagliflozin once daily in patients with type 2 diabetes," Diabetes, Obesity and Metabolism, vol. 15, no. 7, pp. 613-621, 2013.

[76] B. Komoroski, N. Vachharajani, D. Boulton et al., "Dapagliflozin, a novel SGLT2 inhibitor, induces dose-dependent glucosuria in healthy subjects," Clinical Pharmacology \& Therapeutics, vol. 85, no. 5, pp. 520-526, 2009.

[77] S. Sha, D. Devineni, A. Ghosh et al., "Canagliflozin, a novel inhibitor of sodium glucose co-transporter 2, dose dependently reduces calculated renal threshold for glucose excretion and increases urinary glucose excretion in healthy subjects," Diabetes, Obesity and Metabolism, vol. 13, no. 7, pp. 669-672, 2011.

[78] T. Nagata, M. Fukazawa, K. Honda et al., "Selective SGLT2 inhibition by tofogliflozin reduces renal glucose reabsorption under hyperglycemic but not under hypo- or euglycemic conditions in rats," The American Journal of Physiology - Endocrinology and Metabolism, vol. 304, no. 4, pp. E414-E423, 2013.

[79] B. N. Mkhwanazi, M. R. Serumula, R. B. Myburg, F. R. Van Heerden, and C. T. Musabayane, "Antioxidant effects of maslinic acid in livers, hearts and kidneys of streptozotocininduced diabetic rats: effects on kidney function," Renal Failure, vol. 36, no. 3, pp. 419-431, 2014.

[80] P. S. Ngubane, S. I. Hadebe, M. R. Serumula, and C. T. Musabayane, "The effects of transdermal insulin treatment of streptozotocin-induced diabetic rats on kidney function and renal expression of glucose transporters," Renal Failure, vol. 37, no. 1, pp. 151-159, 2015.

[81] J. Sokolovska, S. Isajevs, O. Sugoka et al., "Comparison of the effects of glibenclamide on metabolic parameters, GLUT1 expression, and liver injury in rats with severe and mild streptozotocin-induced diabetes mellitus," Medicina, vol. 48, no. 10, p. 78, 2012.

[82] J. Sokolovska, S. Isajevs, O. Sugoka et al., "Correction of glycaemia and GLUT1 level by mildronate in rat streptozotocin diabetes mellitus model," Cell Biochemistry and Function, vol. 29, no. 1, pp. 55-63, 2011.

[83] J. B. Jamuna and C. D. Nandini, "Feeding of banana flower and pseudostem to diabetic rats results in modulation of renal GLUTs, TGF $\beta$, PKC and extracellular matrix components," Nutrition, Metabolism, and Cardiovascular Diseases, vol. 24, no. 6, pp. 623-631, 2014.

[84] V. Vallon, M. Gerasimova, M. A. Rose et al., "SGLT2 inhibitor empagliflozin reduces renal growth and albuminuria in proportion to hyperglycemia and prevents glomerular hyperfiltration in diabetic Akita mice," The American Journal of Physiology - Renal Physiology, vol. 306, no. 2, pp. F194F204, 2014.

[85] V. Vallon, M. Rose, M. Gerasimova et al., "Knockout of Naglucose transporter SGLT2 attenuates hyperglycemia and glomerular hyperfiltration but not kidney growth or injury in diabetes mellitus," The American Journal of Physiology Renal Physiology, vol. 304, no. 2, pp. F156-F167, 2013.

[86] J. Chang, Y. Zhou, G. Cong et al., "Dendrobium candidum protects against diabetic kidney lesions through regulating vascular endothelial growth factor, Glucose Transporter 1, and connective tissue growth factor expression in rats," Journal of Cellular Biochemistry, vol. 120, no. 8, pp. 13924-13931, 2019.

[87] M. S. Souza, U. F. Machado, M. Okamoto et al., "Reduced cortical renal GLUT1 expression induced by angiotensinconverting enzyme inhibition in diabetic spontaneously hypertensive rats," Brazilian Journal of Medical and Biological Research, vol. 41, no. 11, pp. 960-968, 2008.

[88] B. Deepa and C. V. Anuradha, "Effects of linalool on inflammation, matrix accumulation and podocyte loss in kidney of streptozotocin-induced diabetic rats," Toxicology Mechanisms and Methods, vol. 23, no. 4, pp. 223-234, 2012.

[89] H. K. Sun, Y. M. Lee, K. H. Han, H. S. Kim, S. H. Ahn, and S. Y. Han, "Phosphodiesterase inhibitor improves renal tubulointerstitial hypoxia of the diabetic rat kidney," The Korean Journal of Internal Medicine, vol. 27, no. 2, pp. 163-170, 2012.

[90] H. Chichger, M. E. Cleasby, S. K. Srai, R. J. Unwin, E. S. Debnam, and J. Marks, "Experimental type II diabetes and related models of impaired glucose metabolism differentially regulate glucose transporters at the proximal tubule brush border membrane," Experimental Physiology, vol. 101, no. 6, pp. 731-742, 2016.

[91] A. S. da Silva, L. D. Dias, J. F. Borges et al., "Renal GLUT1 reduction depends on angiotensin-converting enzyme inhibition in diabetic hypertensive rats," Life Sciences, vol. 92, no. 24-26, pp. 1174-1179, 2013.

[92] C. Jurysta, C. Nicaise, M.-H. Giroix, S. Cetik, W. J. Malaisse, and A. Sener, "Comparison of GLUT1, GLUT2, GLUT4 and SGLT1 mRNA expression in the salivary glands and six other organs of control, streptozotocin-induced and gotokakizaki diabetic rats," Cellular Physiology and Biochemistry, vol. 31, no. 1, pp. 37-43, 2013.

[93] M. G. Komala, S. Gross, H. Mudaliar et al., "Inhibition of Kidney Proximal Tubular Glucose Reabsorption Does Not Prevent against Diabetic Nephropathy in Type 1 Diabetic eNOS Knockout Mice," PLoS One, vol. 9, no. 11, p. e108994, 2014.

[94] D. Álvarez-Cilleros, E. López-Oliva, L. Goya, M. Á. Martín, and S. Ramos, "Cocoa intake attenuates renal injury in Zucker Diabetic fatty rats by improving glucose homeostasis," Food and Chemical Toxicology, vol. 127, pp. 101-109, 2019.

[95] A. David-Silva, H. S. Freitas, M. M. Okamoto, R. SabinoSilva, B. D. Schaan, and U. F. Machado, "Hepatocyte nuclear factors $1 \alpha / 4 \alpha$ and forkhead box A2 regulate the solute carrier 2A2 (Slc2a2) gene expression in the liver and kidney of diabetic rats," Life Sciences, vol. 93, no. 22, pp. 805-813, 2013.

[96] L. D. Dias, K. R. Casali, N. M. Leguisamo et al., "Renal denervation in an animal model of diabetes and hypertension: Impact on the autonomic nervous system and nephropathy," Cardiovascular Diabetology, vol. 10, no. 1, p. 33, 2011.

[97] H. S. Freitas, B. D. Schaan, A. David-Silva et al., "SLC2A2 gene expression in kidney of diabetic rats is regulated by HNF-1 $\alpha$ and HNF-3 $\beta$," Molecular and Cellular Endocrinology, vol. 305, no. 1-2, pp. 63-70, 2009.

[98] C. Ma, J. H. F. de Baaij, P. J. Millar et al., "Effect of Dapagliflozin Treatment on the Expression of Renal Sodium Transporters/Channels on High-Fat Diet Diabetic Mice," Nephron, vol. 142, no. 1, pp. 51-60, 2019.

[99] S. da Silva Teixeira, A. C. Panveloski-Costa, A. Carvalho et al., "Thyroid hormone treatment decreases hepatic glucose 
production and renal reabsorption of glucose in alloxaninduced diabetic Wistar rats," Physiological Reports, vol. 4, no. 18, p. e12961, 2016.

[100] X. X. Wang, J. Levi, Y. Luo et al., "SGLT2 protein expression is increased in human diabetic nephropathy," The Journal of Biological Chemistry, vol. 292, no. 13, pp. 5335-5348, 2017.

[101] S. N. Goyal, N. M. Reddy, K. R. Patil et al., "Challenges and issues with streptozotocin-induced diabetes - A clinically relevant animal model to understand the diabetes pathogenesis and evaluate therapeutics," Chemico-Biological Interactions, vol. 244, pp. 49-63, 2016.

[102] S. Kahraman, C. Aydin, G. O. Elpek, E. Dirice, and A. D. Sanlioglu, "Diabetes-Resistant NOR Mice Are More Severely Affected by Streptozotocin Compared to the Diabetes-Prone NOD Mice: Correlations with Liver and Kidney GLUT2 Expressions," Journal Diabetes Research, vol. 2015, article 450128, 8 pages, 2015.

[103] L. Liljedahl, M. H. Pedersen, J. Norlin, J. N. McGuire, and P. James, "N-glycosylation proteome enrichment analysis in kidney reveals differences between diabetic mouse models," Clinical Proteomics, vol. 13, no. 1, 2016.

[104] Y. Birnbaum, M. Bajaj, H.-C. Yang, and Y. Ye, "Combined SGLT2 and DPP4 Inhibition Reduces the Activation of the Nlrp3/ASC Inflammasome and Attenuates the Development of Diabetic Nephropathy in Mice with Type 2 Diabetes," Cardiovascular Drugs and Therapy, vol. 32, no. 2, pp. 135-145, 2018.

[105] K. Jaikumkao, A. Pongchaidecha, N. Chueakula et al., "Dapagliflozin, a sodium-glucose co-transporter-2 inhibitor, slows the progression of renal complications through the suppression of renal inflammation, endoplasmic reticulum stress and apoptosis in prediabetic rats," Diabetes, Obesity and Metabolism, vol. 20, no. 11, pp. 2617-2626, 2018.

[106] N. M. Tabatabai, M. Sharma, S. S. Blumenthal, and D. H. Petering, "Enhanced expressions of sodium-glucose cotransporters in the kidneys of diabetic Zucker rats," Diabetes Research and Clinical Practice, vol. 83, no. 1, pp. e27-e30, 2009.

[107] S. Li, N. Wang, X. Guo et al., "Fibroblast growth factor 21 regulates glucose metabolism in part by reducing renal glucose reabsorption," Biomedicine \& Pharmacotherapy, vol. 108, pp. 355-366, 2018.

[108] H. Osorio, R. Bautista, A. Rios et al., "Effect of phlorizin on SGLT2 expression in the kidney of diabetic rats," Journal of Nephrology, vol. 23, no. 5, pp. 541-546, 2010.

[109] H. Osorio, R. Bautista, A. Rios, M. Franco, J. Santamaría, and B. Escalante, "Effect of treatment with losartan on salt sensitivity and SGLT2 expression in hypertensive diabetic rats," Diabetes Research and Clinical Practice, vol. 86, no. 3, pp. e46-e49, 2009.

[110] A. Tojo, S. Hatakeyama, M. Nangaku, and T. Ishimitsu, "H +-ATPase blockade reduced renal gluconeogenesis and plasma glucose in a diabetic rat model," Medical Molecular Morphology, vol. 51, no. 2, pp. 89-95, 2018.

[111] H. Umino, K. Hasegawa, H. Minakuchi et al., "High Basolateral Glucose Increases Sodium-Glucose Cotransporter 2 and Reduces Sirtuin-1 in Renal Tubules through Glucose Transporter-2 Detection," Scientific Reports, vol. 8, no. 1, p. 6791, 2018.

[112] H. S. Freitas, G. F. Anhê, K. F. S. Melo et al., "Na+-glucose transporter- 2 messenger ribonucleic acid expression in kidney of diabetic rats correlates with glycemic levels: Involve- ment of hepatocyte nuclear factor- $1 \alpha$ expression and activity," Endocrinology, vol. 149, no. 2, pp. 717-724, 2008.

[113] M. F. A. Borghese, M. P. Majowicz, M. C. Ortiz, M. del Rosario Passalacqua, N. B. S. Speziale, and N. A. Vidal, "Expression and Activity of SGLT2 in Diabetes Induced by Streptozotocin: Relationship with the Lipid Environment," Nephron Physiology, vol. 112, no. 3, pp. p45-p52, 2009.

[114] H. P. Himsworth, "The relation of glycosuria to glycaemia and the determination of the renal threshold for glucose," The Biochemical Journal, vol. 25, no. 4, pp. 1128-1146, 1931.

[115] R. L. Mackay, "Observations on the Renal Threshold for Glucose," The Biochemical Journal, vol. 21, no. 3, pp. 760-764, 1927.

[116] J. J. McPhaul Jr. and J. J. Simonaitis, "Observations on the mechanisms of glucosuria during glucose loads in normal and nondiabetic subjects," The Journal of Clinical Investigation, vol. 47, no. 4, pp. 702-711, 1968.

[117] S. W. Shankel, A. M. Robson, and N. S. Bricker, "On the Mechanism of the Splay in the Glucose Titration Curve in Advanced Experimental Renal Disease in the Rat*," The Journal of Clinical Investigation, vol. 46, no. 2, pp. 164-172, 1967.

[118] C. E. Mogensen, "Maximum Tubular Reabsorption Capacity for Glucose and Renal Hemodynamics during Rapid Hypertonic Glucose Infusion in Normal and Diabetic Subjects," Scandinavian Journal of Clinical and Laboratory Investigation, vol. 28, no. 1, pp. 101-109, 1971.

[119] S. Wolf, K. Rave, L. Heinemann, and K. Roggen, "Renal glucose excretion and tubular reabsorption rate related to blood glucose in subjects with type 2 diabetes with a critical reappraisal of the renal glucose threshold model," Hormone and Metabolic Research, vol. 41, no. 08, pp. 600-604, 2009.

[120] B. Thorens, "Glucose transporters in the regulation of intestinal, renal, and liver glucose fluxes," American Journal of Physiology - Gastrointestinal and Liver Physiology, vol. 270, no. 4, pp. G541-G553, 1996.

[121] N. Nakamura, T. Matsui, Y. Ishibashi, and S. Yamagishi, "Insulin stimulates SGLT2-mediated tubular glucose absorption via oxidative stress generation," Diabetology and Metabolic Syndrome, vol. 7, no. 1, 2015.

[122] C. M. Taniguchi, B. Emanuelli, and C. R. Kahn, "Critical nodes in signalling pathways: insights into insulin action," Nature Reviews Molecular Cell Biology, vol. 7, no. 2, pp. 8596, 2006.

[123] R. A. Haeusler, T. E. McGraw, and D. Accili, "Biochemical and cellular properties of insulin receptor signalling," Nature Reviews Molecular Cell Biology, vol. 19, no. 1, pp. 31-44, 2018.

[124] L. Pirola, A. M. Johnston, and E. Van Obberghen, "Modulation of insulin action," Diabetologia, vol. 47 , no. 2, pp. 170184, 2004.

[125] E. Muscelli, R. Pereira-Moreira, M. Seghieri et al., "Effect of insulin on renal maximum glucose transport capacity in healthy volunteers and patients with type 2 diabetes," Diabetologia, vol. 60, no. S1, pp. 249-250, 2017.

[126] A. I. Mendes, P. Matos, S. Moniz, and P. Jordan, "Protein Kinase WNK1 Promotes Cell Surface Expression of Glucose Transporter GLUT1 by Regulating a Tre-2/USP6-BUB2Cdc16 Domain Family Member 4 (TBC1D4)-Rab8A Complex," The Journal of Biological Chemistry, vol. 285, no. 50, pp. 39117-39126, 2010. 
[127] A. Zambrano, E. Jara, P. Murgas et al., "Cytokine Stimulation Promotes Increased Glucose Uptake Via Translocation at the Plasma Membrane of GLUT1 in HEK293 Cells," Journal of Cellular Biochemistry, vol. 110, no. 6, pp. 1471-1480, 2010.

[128] S. Coffey, T. Costacou, T. Orchard, and E. Erkan, “Akt Links Insulin Signaling to Albumin Endocytosis in Proximal Tubule Epithelial Cells," PLoS One, vol. 10, no. 10, p. e0140417, 2015.

[129] H. Sano, S. Kane, E. Sano et al., "Insulin-stimulated phosphorylation of a Rab GTPase-activating protein regulates GLUT4 translocation," The Journal of Biological Chemistry, vol. 278, no. 17, pp. 14599-14602, 2003.

[130] M. D. Bruss, E. B. Arias, G. E. Lienhard, and G. D. Cartee, "Increased Phosphorylation of Akt Substrate of $160 \mathrm{kDa}$ (AS160) in Rat Skeletal Muscle in Response to Insulin or Contractile Activity,” Diabetes, vol. 54, no. 1, pp. 41-50, 2005.

[131] T. F. Ackermann, K. M. Boini, H. Völkl et al., "SGK1-sensitive renal tubular glucose reabsorption in diabetes," American Journal of Physiology-Renal Physiology, vol. 296, no. 4, pp. F859-F866, 2009.

[132] M. Dieter, M. Palmada, J. Rajamanickam et al., "Regulation of Glucose Transporter SGLT1 by Ubiquitin Ligase Nedd4-2 and Kinases SGK1, SGK3, and PKB," Obesity Research, vol. 12, no. 5, pp. 862-870, 2004.

[133] S. Saad, V. A. Stevens, L. Wassef et al., "High glucose transactivates the EGF receptor and up-regulates serum glucocorticoid kinase in the proximal tubule," Kidney International, vol. 68, no. 3, pp. 985-997, 2005.

[134] J. M. Nizar, B. D. Shepard, V. T. Vo, and V. Bhalla, "Renal tubule insulin receptor modestly promotes elevated blood pressure and markedly stimulates glucose reabsorption," JCI Insight, vol. 3, no. 16, 2018.

[135] P. Chonlaket, T. Wongwan, and S. Soodvilai, "Liver X receptor activation inhibits SGLT2-mediated glucose transport in human renal proximal tubular cells," Experimental Physiology, vol. 103, no. 2, pp. 250-260, 2018.

[136] S. J. Bischoff, M. Schmidt, T. Lehmann et al., "Renal glucose release during hypoglycemia is partly controlled by sympathetic nerves - a study in pigs with unilateral surgically denervated kidneys," Physiological Reports, vol. 3, no. 11, p. e12603, 2015.

[137] S. Macha, R. Koenen, R. Sennewald et al., "Effect of Gemfibrozil, Rifampicin, or Probenecid on the Pharmacokinetics of the SGLT2 Inhibitor Empagliflozin in Healthy Volunteers," Clinical Therapeutics, vol. 36, no. 2, pp. 280-290.e1, 2014.

[138] S. K. Nigam, K. T. Bush, G. Martovetsky et al., “The Organic Anion Transporter (OAT) Family: A Systems Biology Perspective," Physiological Reviews, vol. 95, no. 1, pp. 83-123, 2015.

[139] C. Ghezzi, B. A. Hirayama, E. Gorraitz, D. D. F. Loo, Y. Liang, and E. M. Wright, "SGLT2 inhibitors act from the extracellular surface of the cell membrane," Physiological Reports, vol. 2, no. 6, p. e12058, 2014.

[140] Y. Fu, D. Breljak, A. Onishi et al., "Organic anion transporter OAT3 enhances the glucosuric effect of the SGLT2 inhibitor empagliflozin," American Journal of Physiology-Renal Physiology, vol. 315, no. 2, pp. F386-F394, 2018.

[141] A. Lungkaphin, P. Arjinajarn, A. Pongchaidecha, C. Srimaroeng, L. Chatsudthipong, and V. Chatsudthipong, "Impaired Insulin Signaling Affects Renal Organic Anion Transporter 3 (Oat3) Function in Streptozotocin-Induced Diabetic Rats," PLoS One, vol. 9, no. 5, p. e96236, 2014.
[142] K. Jaikumkao, A. Pongchaidecha, N. Chueakula et al., "Renal outcomes with sodium glucose cotransporter 2 (SGLT2) inhibitor, dapagliflozin, in obese insulin-resistant model," Biochimica et Biophysica Acta (BBA) - Molecular Basis of Disease, vol. 1864, no. 6, Part A, pp. 2021-2033, 2018.

[143] D. Galuska, S. Pirkmajer, R. Barrès, K. Ekberg, J. Wahren, and A. V. Chibalin, "C-Peptide Increases Na,K-ATPase Expression via PKC- and MAP Kinase-Dependent Activation of Transcription Factor ZEB in Human Renal Tubular Cells," PLoS One, vol. 6, no. 12, p. e28294, 2011.

[144] S. Iannello, P. Milazzo, and F. Belfiore, “Animal and human tissue $\mathrm{Na}, \mathrm{K}-\mathrm{ATP}$ ase in normal and insulin-resistant states: regulation, behaviour and interpretative hypothesis on NEFA effects," Obesity Reviews, vol. 8, no. 3, pp. 231-251, 2007.

[145] G. Sweeney and A. Klip, "Regulation of the Na+/K+- ATPase by insulin: Why and how?," in Insulin Action, A. K. Srivastava and B. I. Posner, Eds., pp. 121-133, Springer US, Boston, MA, 1998.

[146] C. Ghezzi, D. D. F. Loo, and E. M. Wright, "Physiology of renal glucose handling via SGLT1, SGLT2 and GLUT2," Diabetologia, vol. 61, no. 10, pp. 2087-2097, 2018.

[147] P. Vague, T. C. Coste, M. F. Jannot, D. Raccah, and M. Tsimaratos, "C-peptide, Na," Experimental Diabesity Research, vol. 5, no. 1, pp. 37-50, 2004.

[148] K. S. Al-Numair, C. Veeramani, M. A. Alsaif, and G. Chandramohan, "Influence of kaempferol, a flavonoid compound, on membrane-bound ATPases in streptozotocininduced diabetic rats," Pharmaceutical Biology, vol. 53, no. 9, pp. 1372-1378, 2015.

[149] S. O. Bashir, "Concomitant administration of resveratrol and insulin protects against diabetes mellitus type-1-induced renal damage and impaired function via an antioxidantmediated mechanism and up-regulation of $\mathrm{Na}+\mathrm{K}+$-ATPase," Archives of Physiology and Biochemistry, vol. 125, no. 2, pp. 104-113, 2019.

[150] V. Javorková, L. Mézešová, J. Vlkovičová, and N. Vrbjar, "Influence of sub-chronic diabetes mellitus on functional properties of renal $\mathrm{Na}(+), \mathrm{K}(+)$-ATPase in both genders of rats," General Physiology and Biophysics, vol. 29, no. 3, pp. 266-274, 2010.

[151] V. Javorková, L. Mézesová, J. Vlkovicová, and N. Vrbjar, "Acute diabetes mellitus and its influence on renal Na,KATPase in both genders," General Physiology and Biophysics, vol. 28, no. 1, pp. 39-46, 2009.

[152] M. D. Morsy, H. A. Abdel-Razek, and O. M. Osman, "Effect of vanadium on renal $\mathrm{Na}+, \mathrm{K}+$-ATPase activity in diabetic rats: a possible role of leptin," Journal of Physiology and Biochemistry, vol. 67, no. 1, pp. 61-69, 2011.

[153] S. Sancar-Bas, S. Gezginci-Oktayoglu, and S. Bolkent, "Exendin- 4 attenuates renal tubular injury by decreasing oxidative stress and inflammation in streptozotocin-induced diabetic mice," Growth Factors, vol. 33, no. 5-6, pp. 419-429, 2015.

[154] Q. Shi, J. Zeng, Y. Dong, and K. Y. Xu, "Concurrent impairment of $\left(\mathrm{Na}^{+}+\mathrm{K}^{+}\right)$-ATPase activity in multi-organ of type1 diabetic NOD mice," Journal of Diabetes and its Complications, vol. 27, no. 1, pp. 29-33, 2013.

[155] S. O. Bashir, M. D. Morsy, H. F. Sakr et al., "Quercetin ameliorates diabetic nephropathy in rats via modulation of renal $\mathrm{NA}^{+}, \mathrm{K}^{+}$-ATPASE expression and oxidative stress," American Journal of Pharmacology and Toxicology, vol. 9, no. 1, pp. 84-95, 2014. 
[156] A. Fekete, K. Rosta, L. Wagner et al., " $\mathrm{Na}^{+}, \mathrm{K}^{+}$-ATPase is modulated by angiotensin II in diabetic rat kidney - another reason for diabetic nephropathy?," The Journal of Physiology, vol. 586, no. 22, pp. 5337-5348, 2008.

[157] M. Moreira-Rodrigues, J. Quelhas-Santos, P. Serrao, C. Fernandes-Cerqueira, B. Sampaio-Maia, and M. Pestana, "Glycaemic control with insulin prevents the reduced renal dopamine D1 receptor expression and function in streptozotocin-induced diabetes," Nephrology, Dialysis, Transplantation, vol. 25, no. 9, pp. 2945-2953, 2010.

[158] N. P. Mikaelian, A. E. Gurina, and A. A. Terent'ev, "Dysfunction of Membrane-Receptor System of Blood Cells and Kidney Tissue in Experimental Diabetes Mellitus," Bulletin of Experimental Biology and Medicine, vol. 154, no. 5, pp. 610-613, 2013.

[159] S. Fakhruddin, W. A. Alanazi, H. N. Alhamami, K. P. Briski, and K. E. Jackson, "Hyperglycaemia induced by chronici.p. and oral glucose loading leads to hypertension through increased $\mathrm{Na}+$ retention in proximal tubule," Experimental Physiology, vol. 103, no. 2, pp. 236-249, 2018.

[160] E. Feraille, S. Marsy, L. Cheval et al., "Sites of antinatriuretic action of insulin along rat nephron," The American Journal of Physiology - Renal Physiology, vol. 263, no. 1, pp. F175F179, 1992.

[161] Y. Yang, C. Chen, C. Fu et al., “Angiotensin II type 2 receptor inhibits expression and function of insulin receptor in rat renal proximal tubule cells," Journal of the American Society of Hypertension, vol. 12, no. 2, pp. 135-145, 2018.

[162] M. A. Gallicchio and L. A. Bach, "Uptake of advanced glycation end products by proximal tubule epithelial cells via macropinocytosis," Biochimica et Biophysica Acta (BBA) Molecular Cell Research, vol. 1833, no. 12, pp. 2922-2932, 2013.

[163] M. A. Gallicchio and L. A. Bach, "Advanced glycation end products inhibit $\mathrm{Na}^{+} \mathrm{K}^{+}$ATPase in proximal tubule epithelial cells: Role of cytosolic phospholipase $\mathrm{A}_{2} \alpha$ and phosphatidylinositol 4-phosphate 5-kinase $\gamma$," Biochimica et Biophysica Acta (BBA) - Molecular Cell Research, vol. 1803, no. 8, pp. 919-930, 2010.

[164] Y. Zhang, H. Ren, X. Lu et al., "Inhibition of D4Dopamine Receptors on Insulin Receptor Expression and Effect in Renal Proximal Tubule Cells," Journal of the American Heart Association, vol. 5, no. 4, 2016.

[165] J. Yang, Z. Cui, D. He et al., "Insulin Increases D5 Dopamine Receptor Expression and Function in Renal Proximal Tubule Cells From Wistar-Kyoto Rats," American Journal of Hypertension, vol. 22, no. 7, pp. 770-776, 2009.

[166] A. A. Banday, "Chronic insulin treatment phosphorylates the renal $\mathrm{Na}$-K-ATPase $\alpha 1$-subunit at serine $16 / 23$ and reduces its activity involving PI3-kinase-dependent PKC activation," American Journal of Physiology-Renal Physiology, vol. 311, no. 5, pp. F958-F966, 2016.

[167] S. Gupta, Y. Yan, D. Malhotra et al., "Ouabain and insulin induce sodium pump endocytosis in renal epithelium," Hypertension, vol. 59, no. 3, pp. 665-672, 2012.

[168] L. Nordquist, K. Shimada, T. Ishii, D. T. Furuya, A. Kamikawa, and K. Kimura, "Proinsulin C-peptide prevents type-1 diabetes-induced decrease of renal $\mathrm{Na}^{+}-\mathrm{K}^{+}$ATPase $\alpha 1$-subunit in rats," Diabetes/Metabolism Research and Reviews, vol. 26, no. 3, pp. 193-199, 2010.

[169] J. E. Gerich, "Role of the kidney in normal glucose homeostasis and in the hyperglycaemia of diabetes mellitus: therapeu- tic implications," Diabetic Medicine, vol. 27, no. 2, pp. 136142, 2010.

[170] M. Alsahli and J. E. Gerich, "Renal glucose metabolism in normal physiological conditions and in diabetes," Diabetes Research and Clinical Practice, vol. 133, pp. 1-9, 2017.

[171] A. Mather and C. Pollock, "Glucose handling by the kidney," Kidney International, vol. 79, pp. S1-S6, 2011.

[172] M. Stumvoll, C. Meyer, A. Mitrakou, V. Nadkarni, and J. E. Gerich, "Renal glucose production and utilization: new aspects in humans," Diabetologia, vol. 40, no. 7, pp. 749757, 1997.

[173] C. von Morze, G.-Y. Chang, P. E. Z. Larson et al., "Detection of localized changes in the metabolism of hyperpolarized gluconeogenic precursors13C-lactate and13C-pyruvate in kidney and liver," Magnetic Resonance in Medicine, vol. 77, no. 4, pp. 1429-1437, 2017.

[174] S. Tiwari, R. S. Singh, L. Li et al., "Deletion of the Insulin Receptor in the Proximal Tubule Promotes Hyperglycemia," Journal of the American Society of Nephrology, vol. 24, no. 8, pp. 1209-1214, 2013.

[175] Y. Wen, N. Lin, H.-T. Yan et al., "Down-regulation of renal gluconeogenesis in type II diabetic rats following Roux-enY gastric bypass surgery: a potential mechanism in hypoglycemic effect," Obesity Facts, vol. 8, pp. 110-124, 2015.

[176] G. Pandey, K. Shankar, E. Makhija et al., "Reduced insulin receptor expression enhances proximal tubule gluconeogenesis," Journal of Cellular Biochemistry, vol. 118, no. 2, pp. 276285, 2017.

[177] K. Winiarska, R. Jarzyna, J. M. Dzik et al., "ERK1/2 pathway is involved in renal gluconeogenesis inhibition under conditions of lowered NADPH oxidase activity," Free Radical Biology and Medicine, vol. 81, pp. 13-21, 2015.

[178] K. Atageldiyeva, Y. Fujita, T. Yanagimachi et al., "Sodiumglucose cotransporter 2 inhibitor and a low carbohydrate diet affect gluconeogenesis and glycogen content differently in the kidney and the liver of non-diabetic mice," PLoS One, vol. 11, no. 6, p. e0157672, 2016.

[179] M. Usarek, A. K. Jagielski, P. Krempa et al., "Proinsulin Cpeptide potentiates the inhibitory action of insulin on glucose synthesis in primary cultured rabbit kidney-cortex tubules: metabolic studies," Biochemistry and Cell Biology, vol. 92, no. 1, pp. 1-8, 2014.

[180] S. Horita, G. Seki, H. Yamada, M. Suzuki, K. Koike, and T. Fujita, "Insulin resistance, obesity, hypertension, and renal sodium transport," International Journal of Hypertension, vol. 2011, 8 pages, 2011.

[181] S. S. Thomas, L. Zhang, and W. E. Mitch, "Molecular mechanisms of insulin resistance in chronic kidney disease," Kidney International, vol. 88, no. 6, pp. 1233-1239, 2015.

[182] E. Ahlqvist, P. Storm, A. Käräjämäki et al., "Novel subgroups of adult-onset diabetes and their association with outcomes: a data-driven cluster analysis of six variables," The Lancet Diabetes and Endocrinology, vol. 6, no. 5, pp. 361-369, 2018.

[183] R. D. Leslie, J. Palmer, N. C. Schloot, and A. Lernmark, "Diabetes at the crossroads: relevance of disease classification to pathophysiology and treatment," Diabetologia, vol. 59, no. 1, pp. 13-20, 2016.

[184] U. Enigk, J. Breitfeld, D. Schleinitz et al., "Role of genetic variation in the human sodium-glucose cotransporter 2 gene (SGLT2) in glucose homeostasis," Pharmacogenomics, vol. 12, no. 8, pp. 1119-1126, 2011. 
[185] C. C. Hsu, W. L. Kao, M. W. Steffes et al., "Genetic variation of glucose transporter-1 (GLUT1) and albuminuria in 10,278 European Americans and African Americans: a case-control study in the Atherosclerosis Risk in Communities (ARIC) Study," BMC Medical Genetics, vol. 12, no. 1, 2011.

[186] I. Stefanidis, K. Kytoudis, A. A. Papathanasiou et al., "XbaI GLUT1 gene polymorphism and the risk of type 2 diabetes with nephropathy," Disease Markers, vol. 27, no. 1, 35 pages, 2009.

[187] L. Li, M. Byrd, K. Doh et al., "Absence of renal enlargement in fructose-fed proximal-tubule-select insulin receptor (IR), insulin-like-growth factor receptor (IGF1R) double knockout mice," Physiological Reports, vol. 4, no. 23, p. e13052, 2016.

[188] D. E. Moller, A. Yokota, J. F. Caro, and J. S. Flier, "Tissue-specific expression of two alternatively spliced insulin receptor mRNAs in man," Molecular Endocrinology, vol. 3, no. 8, pp. 1263-1269, 1989.

[189] S. G. Vienberg, S. D. Bouman, H. Sørensen et al., "Receptorisoform-selective insulin analogues give tissue-preferential effects," Biochemical Journal, vol. 440, no. 3, pp. 301-308, 2011.

[190] S. Seino and G. I. Bell, "Alternative splicing of human insulin receptor messenger RNA," Biochemical and Biophysical Research Communications, vol. 159, no. 1, pp. 312-316, 1989.

[191] M. Nakamura, O. Yamazaki, A. Shirai et al., "Preserved $\mathrm{Na} / \mathrm{HCO}_{3}$ cotransporter sensitivity to insulin may promote hypertension in metabolic syndrome," Kidney International, vol. 87, no. 3, pp. 535-542, 2015.

[192] M. Nakamura, N. Satoh, M. Suzuki et al., "Stimulatory effect of insulin on renal proximal tubule sodium transport is preserved in type 2 diabetes with nephropathy," Biochemical and Biophysical Research Communications, vol. 461, no. 1, pp. 154-158, 2015.

[193] S. Tiwari, V. K. M. Halagappa, S. Riazi, X. Hu, and C. A. Ecelbarger, "Reduced expression of insulin receptors in the kidneys of insulin-resistant rats," Journal of the American Society of Nephrology, vol. 18, no. 10, pp. 2661-2671, 2007.

[194] J. Boucher, A. Kleinridders, and C. R. Kahn, "Insulin receptor signaling in normal and insulin-resistant states," Cold Spring Harbor Perspectives in Biology, vol. 6, no. 1, p. a009191, 2014.

[195] X. J. Sun, J. L. Goldberg, L. Y. Qiao, and J. J. Mitchell, "Insulin-induced insulin receptor substrate-1 degradation is mediated by the proteasome degradation pathway," Diabetes, vol. 48, no. 7, pp. 1359-1364, 1999.

[196] M. Baum, "Insulin stimulates volume absorption in the rabbit proximal convoluted tubule," The Journal of Clinical Investigation, vol. 79, no. 4, pp. 1104-1109, 1987.

[197] C. Meyer, J. Dostou, V. Nadkarni, and J. Gerich, "Effects of physiological hyperinsulinemia on systemic, renal, and hepatic substrate metabolism," The American Journal of Physiology Renal Physiology, vol. 275, no. 6, pp. F915-F921, 1998.

[198] Y. Jia, J. He, L. Wang et al., "Dapagliflozin aggravates renal injury via promoting gluconeogenesis in $\mathrm{db} / \mathrm{db}$ mice," Cellular Physiology and Biochemistry, vol. 45, no. 5, pp. 1747-1758, 2018.

[199] S. Horita, M. Nakamura, M. Suzuki, N. Satoh, A. Suzuki, and G. Seki, "Selective insulin resistance in the kidney," BioMed Research International, vol. 2016, Article ID 5825170, 8 pages, 2016.

[200] M. B. Hookham, H. C. O'Donovan, R. H. Church et al., "Insulin receptor substrate- 2 is expressed in kidney epithelium and up-regulated in diabetic nephropathy," The FEBS Journal, vol. 280, no. 14, pp. 3232-3243, 2013.

[201] O. A. Korkmaz, E. Sumlu, H. B. Koca et al., "Effects of Lactobacillus plantarum and Lactobacillus helveticus on renal insulin signaling, inflammatory markers, and glucose transporters in high-fructose-fed rats," Medicina, vol. 55, no. 5, p. 207, 2019.

[202] Q. Liu, L. Zhang, W. Zhang et al., "Inhibition of NF- $\kappa \mathrm{B}$ reduces renal inflammation and expression of PEPCK in type 2 diabetic mice," Inflammation, vol. 41, no. 6, pp. 2018-2029, 2018.

[203] N. Sahin, C. Orhan, F. Erten et al., "Effects of allyl isothiocyanate on insulin resistance, oxidative stress status, and transcription factors in high-fat diet/streptozotocin-induced type 2 diabetes mellitus in rats," Journal of Biochemical and Molecular Toxicology, vol. 33, no. 7, p. e22328, 2019.

[204] H. Mudaliar, C. Pollock, M. G. Komala, S. Chadban, H. Wu, and U. Panchapakesan, "The role of Toll-like receptor proteins (TLR) 2 and 4 in mediating inflammation in proximal tubules," American Journal of Physiology. Renal Physiology, vol. 305, no. 2, pp. F143-F154, 2013.

[205] J. Kramer, E. L. Moeller, A. Hachey, K. G. Mansfield, and L. M. Wachtman, "Differential expression of GLUT2 in pancreatic islets and kidneys of New and Old World nonhuman primates," American Journal of Physiology. Regulatory, Integrative and Comparative Physiology, vol. 296, no. 3, pp. R786-R793, 2009.

[206] B. K. Nayak, K. Shanmugasundaram, W. E. Friedrichs et al., "HIF-1 mediates renal fibrosis in OVE26 type 1 diabetic mice," Diabetes, vol. 65, no. 5, pp. 1387-1397, 2016.

[207] K. H. Chhabra, J. M. Adams, B. Fagel et al., "Hypothalamic POMC deficiency improves glucose tolerance despite insulin resistance by increasing glycosuria," Diabetes, vol. 65, no. 3, pp. 660-672, 2016.

[208] S. C. Thomson, A. Kashkouli, and P. Singh, "Glucagon-like peptide-1 receptor stimulation increases GFR and suppresses proximal reabsorption in the rat," American Journal of Physiology-Renal Physiology, vol. 304, no. 2, pp. F137-F144, 2013.

[209] Y. Zhao, P. Gao, F. Sun et al., "Sodium Intake Regulates Glucose Homeostasis through the PPAR $\delta /$ AdiponectinMediated SGLT2 Pathway," Cell Metabolism, vol. 23, no. 4, pp. 699-711, 2016.

[210] B. D. Shepard, L. Cheval, Z. Peterlin et al., "A renal olfactory receptor aids in kidney glucose handling," Scientific Reports, vol. 6, no. 1, 2016.

[211] M. J. Coady, A. el Tarazi, R. Santer et al., "MAP17 is a necessary activator of renal $\mathrm{Na}+$ /glucose cotransporter SGLT2," Journal of the American Society of Nephrology, vol. 28, no. 1, pp. 85-93, 2017.

[212] D. Álvarez-Cilleros, M. Á. Martín, and S. Ramos, “(-)-Epicatechin and the colonic 2,3-dihydroxybenzoic acid metabolite regulate glucose uptake, glucose production, and improve insulin signaling in renal NRK-52E cells," Molecular Nutrition \& Food Research, vol. 62, no. 4, p. 1700470, 2018. 


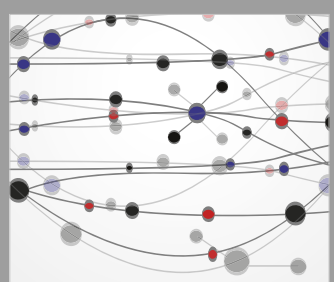

The Scientific World Journal
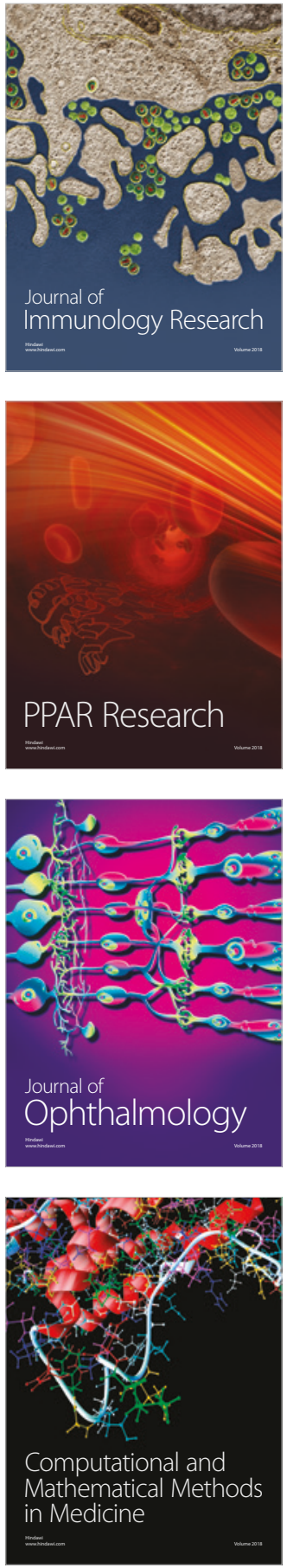

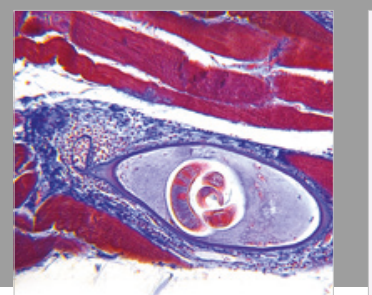

Gastroenterology Research and Practice

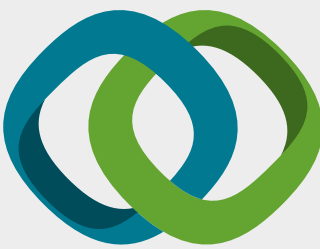

\section{Hindawi}

Submit your manuscripts at

www.hindawi.com
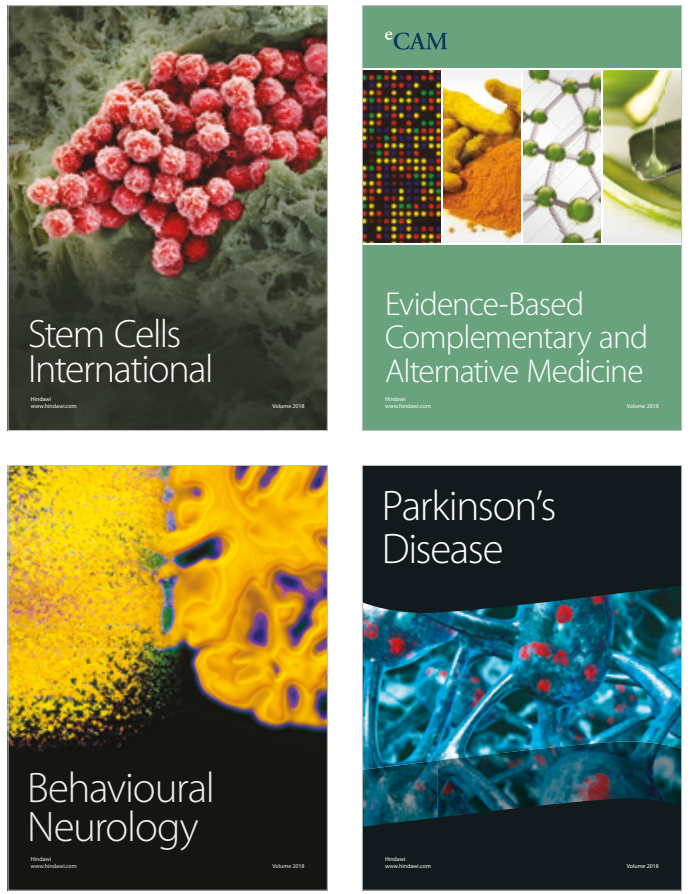

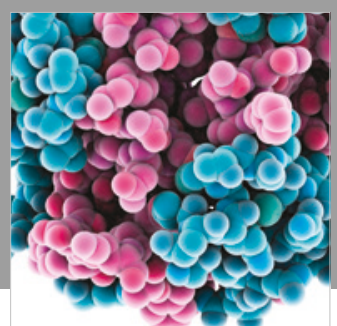

ournal of

Diabetes Research

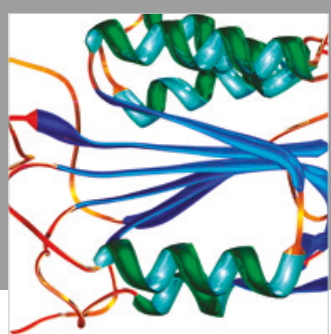

Disease Markers
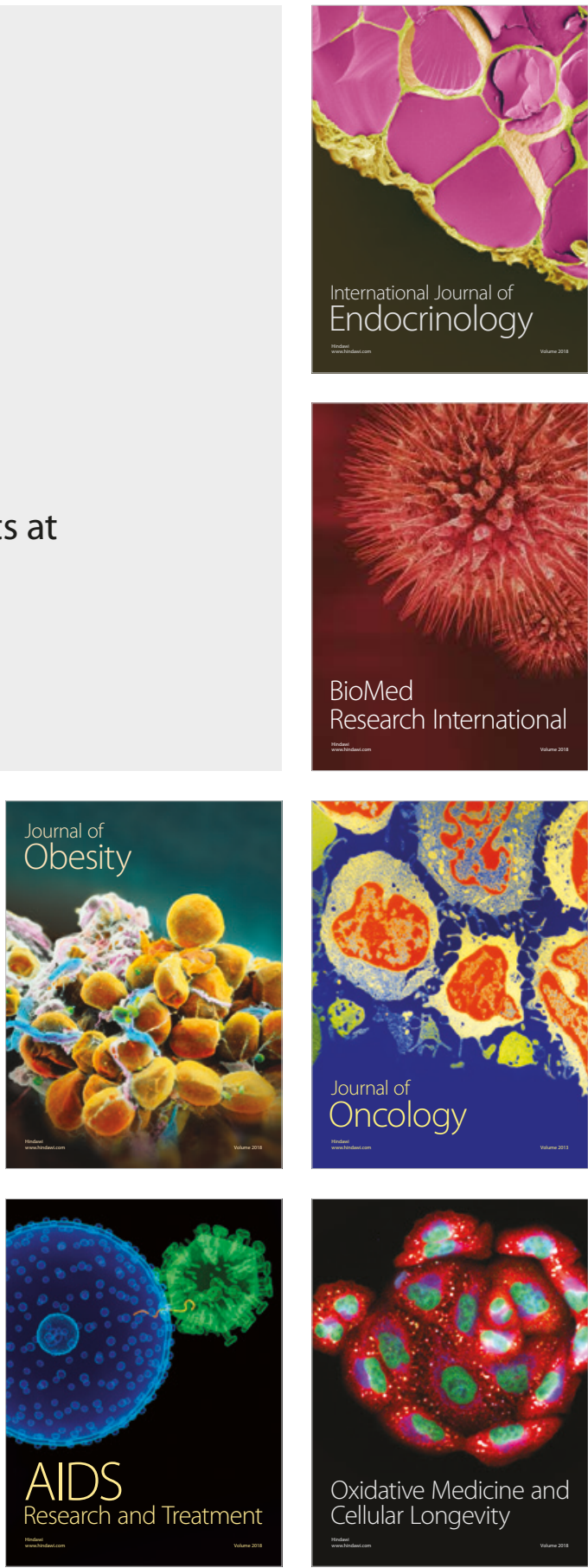